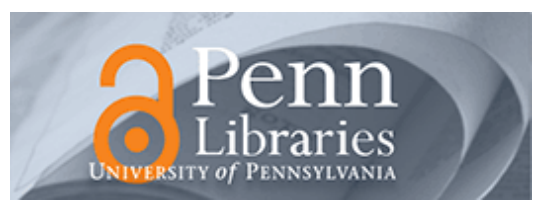

Studies in Visual Communication

Volume 2

Issue 1 Spring 1975

Article 4

1975

\title{
Art as a Structural System: A Study of Hopi Pottery Designs
}

Laura J. Greenberg

\section{Recommended Citation}

Greenberg, L. J. (1975). Art as a Structural System: A Study of Hopi Pottery Designs. 2 (1), 33-50.

Retrieved from https://repository.upenn.edu/svc/vol2/iss1/4

This paper is posted at ScholarlyCommons. https://repository.upenn.edu/svc/vol2/iss1/4

For more information, please contact repository@pobox.upenn.edu. 
Art as a Structural System: A Study of Hopi Pottery Designs

This contents is available in Studies in Visual Communication: https://repository.upenn.edu/svc/vol2/iss 1/4 


\section{ART AS A STRUCTURAL SYSTEM: A STUDY OF HOPI POTTERY DESIGNS ${ }^{1}$}

\section{LAURA J. GREENBERG}

\section{WORKING HYPOTHESES: THE RESEARCHER}

It is Arnheim's (1966) working hypothesis that art reflects not one but two processes of abstraction, namely: (1) the abstraction entailed in visual perception which requires that one order and classify in order to perceive, and (2) the abstraction entailed in devising any visual representations ("realistic" or otherwise). Thus:

There is no direct transformation of experience into form, but rather a search for equivalents [Arnheim 1966:266] .

Also, perhaps, in the realm of "working hypothesis" is the Sapir-Whorf Hypothesis, which speculates on the nature of the relationship between language and thought. Although the specific formulations of this hypothesis vary (Whorf 1940, 1941; Sapir 1929:209), there is a general connection posited between a language's lexation and grammatical structure, and the content of thought. In other words, one's linguistic categories and discriminations presumably influence what one will in fact think, and vice verse.

This paper ultimately derives from my interest in the relationship between these two working hypotheses. Although one evolved in the discipline of linguistics and the other in the context of the psychology of art, they seemed to contain possible congruences. In particular, I was interested in the possible implications of each for the other. It seemed that if Whorf were correct about language affecting the way people classify and order reality, and if Arnheim were right about perception necessarily entailing classification and ordering of "visual" reality, then there ought to be the equivalent of a visual Whorf hypothesis. That is, if perception entails active classification and ordering, and if classifications (lexicon) and rules of ordering (as evidenced in grammatical structure) vary from culture to culture, then one would expect visual perceptions to vary cross-culturally in some patterned way as well. Further, it would be logical to expect

Laura Greenberg is a graduate student in anthropology at the University of British Columbia. She is, at the moment, engaged in writing a doctoral dissertation on the structural analysis of the art of the Northern Northwest Coast of America, which focuses on the cognitive operations of inversion and intersection as they are used to generate the art, and on the specific and prolific use of visual punning for social and symbolic ends. that visual discriminations and categories would influence (and be influenced by) art and other "expressive" visual systems (e.g., architectural systems) or systems of spatial terminology, and by language. Secondly, the methodology of linguistics, which so elegantly arrives at system by the ordered and "scientific" study of variation, seemed to have the potential for elucidating these visual systems.

I devised a specific project which attemped to examine and/or verify the above hypothesized connections, choosing the Hopi as a case study, and basing my methodology on linguistic methodology (with some necessary modifications). My choice of the Hopi, specifically Hopi pottery designs, had been motivated by two considerations: (1) that the art system or corpus be relatively abstract or non-representative (thus minimizing semantic meaning as a consideration and maximizing "visual" considerations), and (2) that the people have a relatively well-integrated, coherent, and self-contained philosophy and social structure. As a logical first step in constructing the total design system, I proposed isolating what I called "visual phonemes" in Hopi pottery designs (a term derived from the "new archeologists").

Art is, no doubt, a "language"; however, I realized that the linguistic analogy is a difficult one to translate into visual terms. For one thing, language is, by necessity, a more conventionalized system than art. And for another, whereas the given in linguistics is that humans are physiologically capable of producing only a finite number of mono-syllabic sounds which can be taken as the basic components of any language, such obvious and discrete units are not inherent in the visual realm. And yet, I thought that these and other obstacles could be circumvented by the careful construction of a series of test drawings (based on patterned variations of actual Hopi designs), which could then be used to determine "significant variation" and thus to isolate visual phonemes.

Aside from certain pragmatic considerations, such as having no Hopi contacts when I arrived in Arizona, two factors ultimately caused me to abandon my search for visual phonemes and to reconsider my theoretical model. The first was that it became disconcertingly and progressively more apparent, the more I read and the more I saw of Hopi designs, that my model (which was based on the primacy of units or elements) was antithetical to the nature of Hopi art and to Hopi culture as well (which stresses the primacy of the total). This is, incidentally, an important point, and one which will be further developed in the body of this paper.

The second mitigating factor evolved as I abandoned my quest for visual phonemes, and set about examining the pots in the Museum of Northern Arizona in an effort to study actual variation in pottery designs. As I studied the designs I photographed them as a way of recording them, and in addition, I often drew them. In drawing them, a certain logic or conceptual order began to emerge in what had previously appeared to be fairly chaotic designs. In order to reproduce a design, it is necessary to actively perceive it, i.e., to either discern or create spatial relationships and order in the design, such that it can be recreated. (Reproducing from memory alone would require an even more exacting perception). Thus, it was not surprising that the designs became clearer as I drew them. What was more surprising was that the order in most cases was actually quite simple; it had eluded me so entirely before I was forced to search it out, only because it 
followed different tendencies than those I was used to. For example, although I would have been aware of the symmetry of a bilaterally symmetric design at first glance, I was at first totally oblivious of designs which possessed other sorts of symmetries, such as rotational symmetry. What was most important was that as I drew I began to discern certain structural similarities between designs which had previously seemed to have not a single thing in common. The fact that these previously confusing designs could all be made comprehensible by the same ordering principles suggested that these principles were not totally arbitrary, but perhaps represented a valid structure. All of which suggested the use of a structural model.

Structural analysis seemed an appropriate solution to my problems if for no other reason than because structura! linguistics, which Lévi-Strauss (1967:32) credits as the inspiration for his own structuralist approach, entailed a similar shift from analysis of terms to analysis of relationships between terms. This shift, plus the shift in emphasis from conscious phenomena to unconscious infrastructure, the discovery of general laws, and the search for system (Lévi-Strauss 1967:31) seemed relevant to the patterns I was discovering in Hopi designs.

In addition, that aspect of Lévi-Strauss' thinking which surfaced in The Savage Mind (1966) seemed potentially compatible with part (and only part) ${ }^{2}$ of Arnheim's visual model; there is no direct transformation of experience into form, but rather a search for equivalents. Taken together, they suggest an interesting framework.

It would seem that the tendency to order and structure would be a basic cognitive process which is used by man to apprehend his universe, and that art could be thought of as an external form of this internal process. As such, it would seem useful to analyze an art system in terms of structure. In particular, "the search for equivalents" might be structural, i.e., there might be structural symbolism. This seemed especially likely given the susceptibility of structural relationships to visual or "schematic" representation.

In The Savage Mind (1966), Lévi-Strauss examines the organization of totemic systems, and classifications of the biological world. These are significant, not in what each category includes, but rather in terms of the total system (and the types of discriminations which are thereby made visible). And similarly, in The Elementary Structures of Kinship (1969), he again expresses interest not so much in the individual kinship categories per se, but rather in the total systems which are thereby elucidated, and (most importantly) in the implied structure of those systems.

In analyzing Hopi designs, I have attempted a structural analysis - the visual corollary of a structural linguistic analysis. How are a specific set of Hopi designs organized, what is their visual structure, what organizing principles are evident, and what sorts of discriminations do these organizing principles imply? Secondly, how do these organizing principles correlate with those of other Hopi sub-systems, e.g., the Hopi cosmological system or the Hopi linguistic system? And lastly, how valid is this approach: i.e., what questions (anthropological or otherwise) does it address, what kind of answers does it provide, and what further questions are in turn generated by those answers?
HISTORICAL AND MATERIAL CONTEXTS: THE HOPI ${ }^{3}$

\section{Brief History of Pottery-Making in the Area ${ }^{4}$}

The Hopi are a Pueblo group living in what is now Arizona. Pottery-making has been practiced in the area for the past 15 centuries, and as early as A.D. 600 pottery was being produced in a variety of colors by people alleged to be ancestors of the Hopi (Bartlett 1936:1). However, although occupation of the sites seems to have been nearly continuous, the history of the area (like the history of any area) seems to have been somewhat erratic. One result has been a series of distinct pottery types of varying color, shape, and design, which archeologists have been able to distinguish and to sequence. In its most basic form, the historical sequence of pottery types has been summarized by Bunzel (1929:81) as follows:

I. Black on white period. Entirely geometric ornament.

II. Late prehistoric period. A gradual development of colored wares and animal ornament, reaching its highest development at Sityatki village.

III. Historic period. A gradual return to white wares and geometric ornament.

IV. Contemporary. A recent revival of II.

The pottery that I have analyzed comes exclusively from the last of these periods. Much of the pottery was produced after the above classification was in print, some as late as 1970. However, many of the designs have been adapted from earlier designs. This is in part inherent in the nature of Hopi pottery design, which reflects a series of historical intrusions, interruptions, and fortuitous influences.

For example: The advent of the Spanish in the seventeenth century is thought to have resulted in a degeneration of Hopi pottery; the founding of the First Mesa town of Hano by a group of migrating Tewa in the eighteenth century is thought to have revived the industry; and Zuni patterns are thought to have been incorporated into Hopi pottery as a result of the nineteenth century drought which caused the Hopi to seek refuge in Zuni territory.

Even archeology has not been without its effect. In the late nineteenth century, the archeologist J. Walter Fewkes started excavating a site named Sityatki, and unearthed some spectacular pottery. The wife of one of the archeological fieldworkers, Nampeyo, became interested in the pottery sherds; she first began copying the patterns, and later adapted them to create her own designs. She has been followed by later generations of Nampeyos who have followed the tradition. (The pot shown in Figure 10 is, incidentally, a Nampeyo pot).

Nor does Nampeyo's "Sityatki Revival" represent the last of the fortuitous influences. The tourist trade in the twentieth century affected the kinds of pottery produced, and no doubt the present resurgence of interest in Native American cultures is currently having a similar effect. All of which is described in this section in order to show that, although the Hopi and their ancestors have been producing painted pottery for the last several centuries, the design system has not by any means remained constant nor has it 
developed smoothly. But for all that the influences were fortuitous, the important point in this context is that their effects do not seem to have been totally random. Rather, they all seem to have been incorporated in selectively Hopi ways.

\section{Pottery Technology}

Despite the complexity of the pottery patterns, the technology which the Hopi employ to produce pottery is relatively simple (which is not to say easy). Traditional pottery is still made by women, using neither wheel nor kiln. Using the coil method, the potters progressively add rounds of clay to a base, smoothing each piece into the preceding layer. The walls of the vessel are later thinned and evened with a gourd scraper. After drying, undecorated utility wares are fired directly, while decorated wares may first be slipped with several thin layers of one of the other clays. Finally, the designs are applied with brushes. (It is only this last process with which this paper will be concerned.)

\section{Pottery Shapes and Designs: A Broad Typology}

Hopi pottery is made in a variety of forms: low, shallow, corn-meal bowls; slightly higher, broad-lipped stew bowls; narrow-necked water jugs; and such additional items as ladles, tiles, and canteens. Further, the shapes of the vessels are relevant to a discussion of the designs which are found on them. As one would expect, certain types of designs are more frequently associated with one type of vessel than another, since the design fields vary with the shape of the pot.

There have been many attempts at classification of Pueblo pots by shape and design. Most of these typologies are archeological typologies whose avowed purpose is to differentiate pots, usually by approximate date and area. By contrast, my intention here is to show what Hopi pots, or rather their designs, have in common. The purpose of this typology is to give the reader a general idea of the design solutions which the Hopi have employed.

I am following Bunzel's general prescription that designs are essentially organized around the "roadline" (1929:13), and am basing my categories on the placement of designs in relation to the "roadline" of the pot or of an equivalent line. The "roadline," which Bunzel translated from the Zuni word omane (road), is simply the line that encircles the neck of those pots which have necks and circumscribes the interior of those pots which are too shallow to have necks (e.g., bowls). Although Bunzel systematized possible design arrangements, these were too limited for my purposes as she dealt with only two types of pots: the water jug, and the shallow bowl. I did, however, try to follow her general parameters of variation in the formation of the typology which follows, i.e., amount and part of the field filled, number and type of band groupings, and number and type of repetitions.

\section{General Design Typology:}

I. Pottery with bounded panel designs. Bounded in this case means that the design field is specifically defined by, and generally contained within, encircling lines. These lines are the "roadline" and secondary lines.

A. Pottery with basically one main circumferential band. The circumferential band is a common feature of Hopi pottery. It either occurs on the exterior circumference of a vessel or along the interior rim (and around the border in the case of tiles). I refer to further divisions of this band either as reflecting "vertical," "horizontal," or "oblique" divisions panels, following Bunzel (1929:13-48). In some pots, there is an additional and smaller horizontal band around the neck.

1. Designs with one main horizontal band which is vertically sub-divided. The vertical divisions produce individual design panels. These vary from two to eight in number (and perhaps even more). They are of various arrangements:

(a) One panel repeated several times. This is one of the simplest and most common arrangements. The panels are often further sub-divided along a diagonal.

(b) Alternating panels (two or more). Rather than merely repeating the same design pattern, two or more design patterns are alternated. Thus reading around the pot or tile one would have one panel with design $A$, then one with design $B$, then design $A$, then $B$, etc. Or one could have $A B C A B C$, etc. And once again, the panels are often sub-divided along a diagonal.

(c) More complex alternating panels. These pots are basically of the same type as the ones above, but the panels which repeat are more elaborately sub-divided into horizontal, vertical, and oblique sub-panels.

(d) Alternating fixed and progressive panels. A fixed panel refers to one which is repeated exactly, and a progressive panel is one which varies slightly each time it appears. The variation can result from color being used differently. This is fairly uncommon.

(e) Non-repeating or irregularly-repeating panels. With only one or two possible exceptions, I have not seen pots of this type, but I included this as a residual category.

2. Designs with one horizontal band with no explicit divisions.

(a) Continuous patterns. These are patterns which are composed of a repeating pattern which forms a single connected unit. A scroll or meander would be a good example.

(b) Dis-continuous patterns. These are patterns which are composed of discrete elements but which are so arranged that each pattern leads into the next.

B. Pottery with circular interior areas which are panelled.

1. Designs with two or more main panels, which may or may not be sub-divided. The major division is generally made with a line which is not a 
diameter, and so the panels defined are almost never equal. The panels can either be treated as bounded fields (i.e., sub-divided), or treated as semi-bounded fields.

2. Designs with more than two main panels, arranged rotationally. In designs with more than two main panels, the arrangement is often rotational. In such designs panels are created by the intersection of several lines, none of which is a diameter of the circular area. The panels produced are equal in area, and generally identical as well.

3. Designs with center or near-center radically divided panels. I came across only one pot of this type, which was a canteen, executed in such a way as to suggest an animal face.

II. Pottery with semi-bounded, non-panel designs. These are designs which are bounded only by one line, the "roadline," and no bottom restricting line. Or, in the case of interior designs, these are non-panel designs emerging from the "roadline." By the term "semi-bounded," I definitely mean to imply that it is the encircling line which is the basis of the design's organization. Designs of this type vary considerably, however:

A. Pottery with regular, repetitive designs originating from the roadline. These are generally exterior circumferential designs, and are often quite similar to the designs in I.A.2., except that they are bounded on only one side.

B. Pottery with irregular, non-repetitive designs originating from the "roadline." These can be either exterior or interior designs, and are practically all fairly birdlike, with obvious wings and body forms which are themselves composed of smaller panel sections. In such cases too, there is often at least part of the "roadline" which has no protruding design. Many Sityatki derived pots are of this form.

III. Pottery with unbounded, central designs. This category applies to designs which, though they may be on a pot which is circumscribed by a "roadline," are not attached to it and do not emanate from it. If there is a "roadline," it is somewhat extraneous to the rest of the design.

A. Pottery with one central, free-floating design figure, generally a conventionalized representational figure. These designs are usually standard bird or kachina figures, and occupy the central area of an interior design space. In the case of an exterior design these are usually repeated twice, although only one figure can be seen from any viewpoint.

B. Pottery with repetitive or periodic design patterns, generally organized from the center. Occasionally interior designs are created by organizing periodic band designs around the center of the vessel (as opposed to organizing them from the circumference). Designs of this type can be quite elaborate. In the few cases where non-bounded designs are exterior designs, they generally consist of small isolated design groups occurring two or more times around the exterior of a shallow bowl for which most of the design interest is in the interior pattern.
Symbolism: Dominant or Incidental

One of the premises of a structural study is that the relationships between elements are ultimately more revealing than the elements themselves. Since I had proposed to study Hopi pottery designs as an independent, or at least autonomous, system (not dependent on other systems for meaning), I felt compelled to consider the extent to which Hopi designs employ conventional symbolism or symbolic elements (such that the semantic meaning of elements could be a mitigating factor in the relationship between elements). By the term conventional symbolism, I mean nothing more than what Bunzel calls "the [fixed] association between designs and ... ideas" (1929:70), or what could be called a conventionalized and conscious association between a visual form and meaning; i.e., a symbol's iconic content, or agreed-upon semantic meaning.

Whereas the literature reflected nearly universal agreement as to the beauty of Hopi pottery, and only minor discrepancies as to the nature of its manufacture; on the matter of whether the designs carry meaning there seemed to be bitter disagreement, verging on ideological warfare. The views ranged from those who implied that Hopi art is totally governed by symbolism to the extent that aesthetics or "sensuous pleasure in beauty of form and color" is quite secondary (Hough 1919:268), to those who intimated that the very idea that Hopi pottery designs are symbolic was foisted upon the buying public by unscrupulous traders (Sikorski 1968:20). In the middle were those who suggested that truly symbolic design elements are used only on ceremonial objects, but that the forms (and not the meaning) may also be carried over into a purely decorative context as an alternative to creating new elements (Hubert 1937:2).

One of the earliest contributors to this controversy was the aforementioned Fewkes $(1898,1910)$, who traced Hopi bird, butterfly, and feather symbolism from ancient to recent times, in the art and in a ceremonial and religious context, and imputed a connection between the two. As it happens, many contemporary pots do seem to carry designs which are easily recognizable as conventionalized bird forms. In addition, many pots which do not have avian figures do seem to have avian forms. These might not be recognizable as such but for their clear resemblances to earlier and more explicit avian forms. One can find such derived forms in contemporary pots (see, for example, Figures 2 and 18).

For the sake of argument, I accepted as fact that certain avian and feather symbolism did exist, at least at one time in the past, and further that these avian or feather elements have been carried over into modern designs, in form if not in content. And so the question of whether pottery designs were originally symbolic became non-problematic. What became more problematic was whether designs and design elements still carry symbolic meaning (primarily of a religious or sacred nature) and, if so, to what extent it dictates the placement of elements in any design.

To answer this last set of questions, I turned to Ruth Bunzel's (1929) study of Pueblo pottery. In reference to the Zuni, and with the two exceptions of the "road" or "roadline" and a specific "prayer-stick" design (1929:69-70), she discusses the matter of symbolism as follows: 
[the names which refer to designs] are not pattern names, since they are so loosely applied that there is no definite association between any name and a particular form. The same name is applied. to elements having nothing in common from a stylistic point of view, and conversely, the same element may be differently designated in different contexts. Nor are the designs symbols in any sense of the word. We are justified in using the word symbol only where the associations between the design and the object or idea suggested is fixed and recognized [1929:69; italics my own].

The above was written in reference to the Zuni; as for the Hopi, she suggests that "the associations between designs and objects or ideas is even more tenuous than at Zuni" (1929:70). On another occasion she states outright that "[religious] symbolism plays no role in decoration" among the Hopi (1929:52). In addition, she offers the following comment with specific reference to Fewkes:

There is no reason to assume that the meanings now attached to Sityatki designs are those originally associated with them, nor is any such claim made by the persons who use them.... The modern Hopi sees rainbows and mountains where the archeologist sees birds and serpents. One can take one's choice [Bunzel 1929:71].

Thus, not only does it seem that symbolism was not a factor in Hopi pottery designs at the time Bunzel did her fieldwork; there is even some doubt as to whether it ever was a factor (cf. Bunzel 1929:69-71). This conclusion justified discounting the possibility that Hopi pottery designs are regulated by what would be primarily "non-visual" constraints, i.e., constraints dictated by religious or other meanings. Such constraints would have either diminished the value of a "visual" structural analysis of the corpus (since non-visual constraints would have been operative), or have made it considerably more complicated.

In fact, not only did the literature not diminish the case for a visual structural analysis of Hopi art; it seemed, if anything, to strengthen the case for pursuing a line of analysis which would concentrate on relationships between elements rather than on elements themselves. For while certain forms had been taken over or adapted from other pueblo groups (e.g., the Zuni) and from at least one defunct site (Sityatki), and possibly even from a ceremonial context as suggested by Hubert (1937:2), the linguistic terms which refer to these elements or configurations remained ambiguous and non-specific. It was reported, for example, that a form could be given one name in one context, and a different name in a different context, and still a third name in the first context after a lapse of time (cf. Bunzel 1929:53-54). This inexactitude in naming elements, as well as the fact that they seem to be taken over rather than invented, could be thought to indicate that the elements are not themselves important as entities. Rather, spatial relationships between elements and generating placement of elements may be more important.

This seems quite possible given the precise terminology for describing spatial concepts:

There is a notable paucity of terms of a purely descriptive character, such as square, circle, triangle, and the like, although the language is not lacking in precise terminology for spatial concepts [Bunzel 1929:54].

It seems still more possible in light of the fact that the Hopi language has a preference for verbs as opposed to our favoring nouns, and thus seems to turn our propositions about things into propositions about events (Whorf 1950:70). Interestingly enough (and perhaps as a fitting allegory for anthropology), Bunzel drew entirely different conclusions from the inconsistent design terminology but precise spatial terminology. She suggested that the lack of a consistent linguistic terminology for design elements indicates that art is not the object of rational thought among the Pueblo Indians (Bunzel 1929:54); whereas, on the basis of the same information, I suggest the possibility that it is rational, but that the rationale used is based more on process and relationships than on elements or things. It was with that possibility in mind that I started my structural analysis.

\section{A STRUCTURAL ANALYSIS OF HOPI POTTERY DESIGNS}

\section{Operationalizing Lévi-Strauss}

It may be the general consensus that Lévi-Strauss' ultimate insights are more inspiring than his specific methodology (cf. Hayes and Hayes 1970). Whereas the former are almost indiscriminately applicable, the latter is often exceedingly difficult to apply to any given situation, in part because it is so disturbingly elusive (particularly in his earlier work), and in part because it is so specific. Thus in an effort to operationalize structuralism, I turned to the most concrete and the most relevant strictures I could find-the four basic operations of structural linguistics, as reported by LéviStrauss in Structural Anthropology (1967):

First, structural linguistics shifts from the study of conscious linguistic phenomena to study of their unconscious infrastructure; second, it does not treat terms as independent entities, taking instead as its basis of analysis the relations between terms; third, it introduces the concept of system ... ; finally, structural linguistics aims at discovering general laws, either by induction [or by logical deduction] [Lévi-Strauss 1967:31].

Although the translation of structural linguistic principles into a visual equivalent was not as automatic as one might have hoped, it did at least represent a general strategy. However, there were certain basic problems. Clearly a prerequisite for a decent "structural analysis" of a given design corpus is a general (etic) descriptive system. Just as clearly, such a descriptive system can ultimately be constructed only on the basis of several individual design systems (such as Hopi pottery designs). Further, the existing terminology which I had at my disposal consisted mainly of design terms, e.g., symmetry, balance, rhythm, etc., as well as a few Gestalt relationships like figure-and-ground which had been incorporated into the standard design framework. With the terms, one inherits (unsolicited) an implicit design framework - an entire visual context which is often inapplicable to Hopi designs and sometimes deceptive as well. At times design qualities or characteristics are individually relevant to the Hopi material, but do not relate to each other in the ways that the traditional context implies. Other design concepts are relevant to the Hopi material only because of their conspicuous inapplicability.

And so I was left with essentially two options. I could (theoretically) invent an entirely new system of design terms with which to analyze Hopi art, or I could use the old design terms with the advance warning that I would be abandoning 


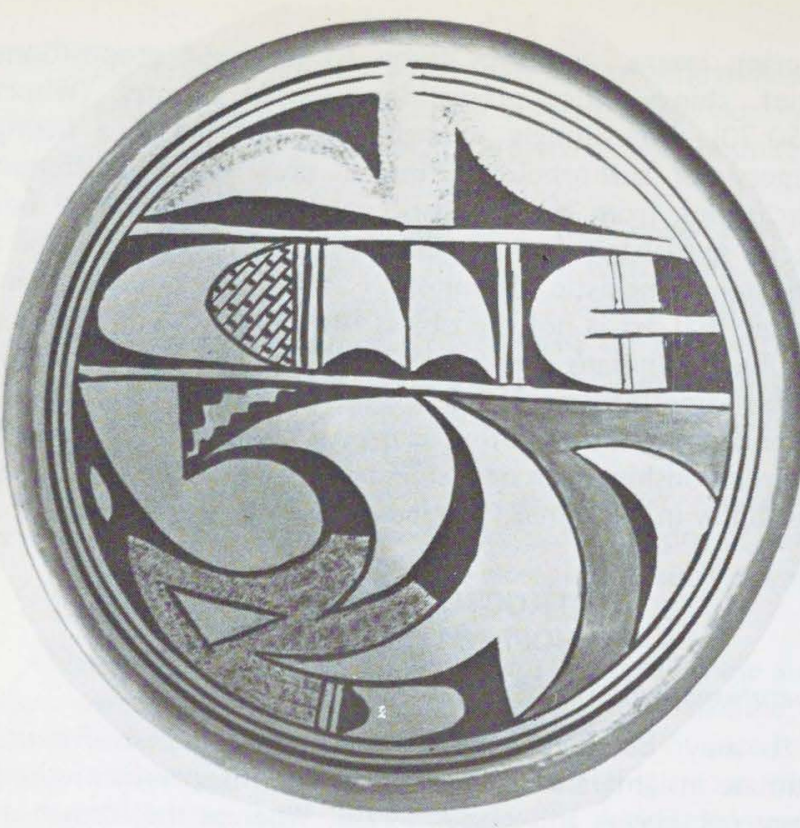

Figure 1

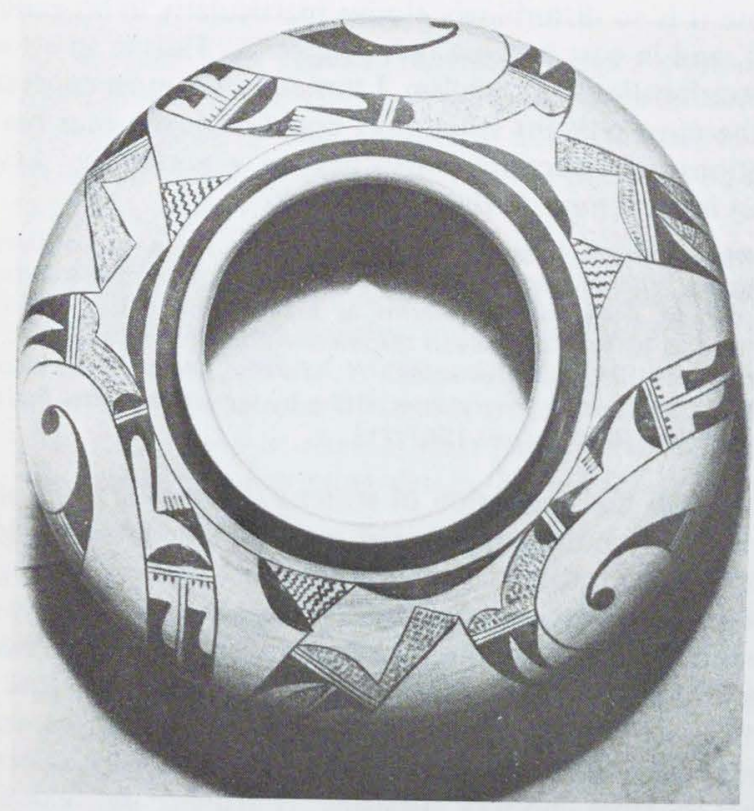

Figure 2

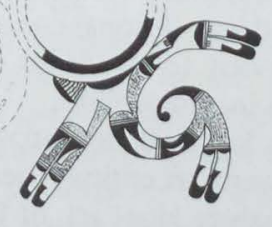

Figure 3

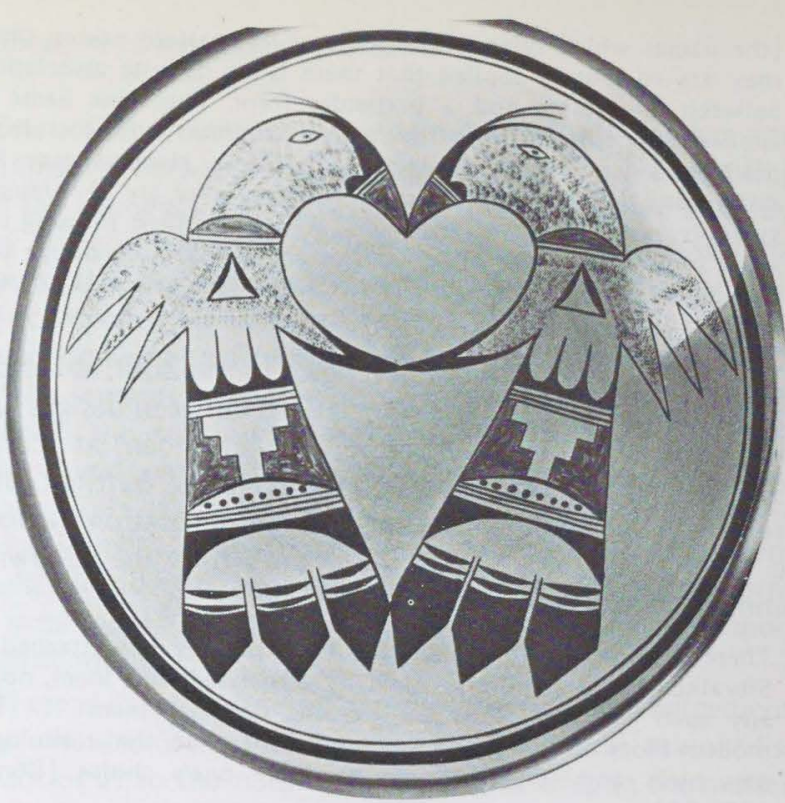

Figure 4
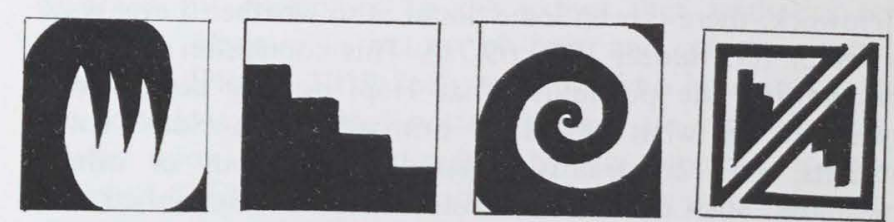

Figure 5

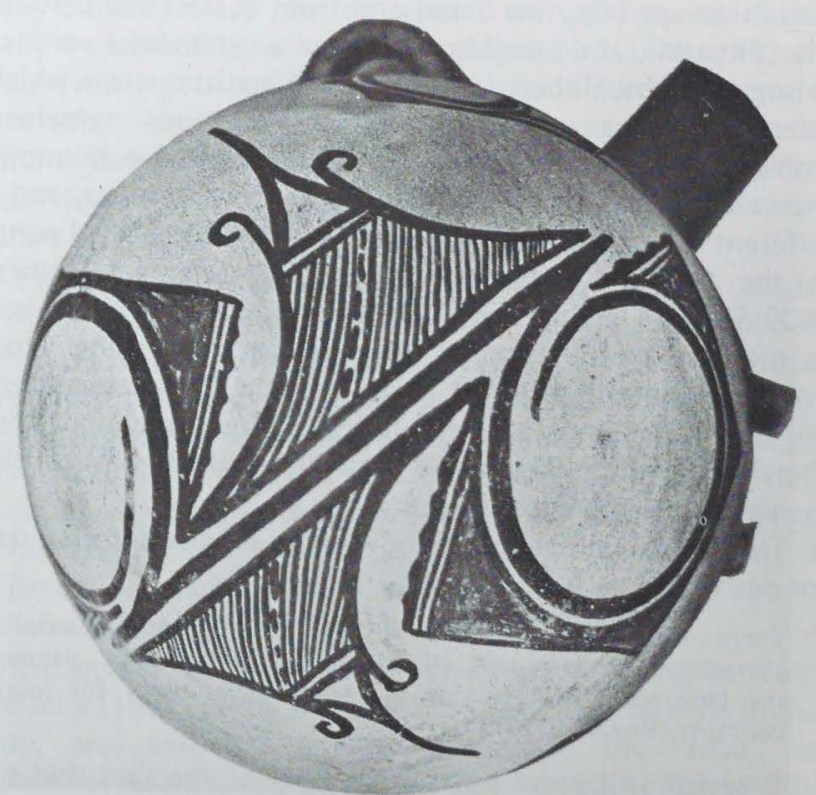

Figure 6 


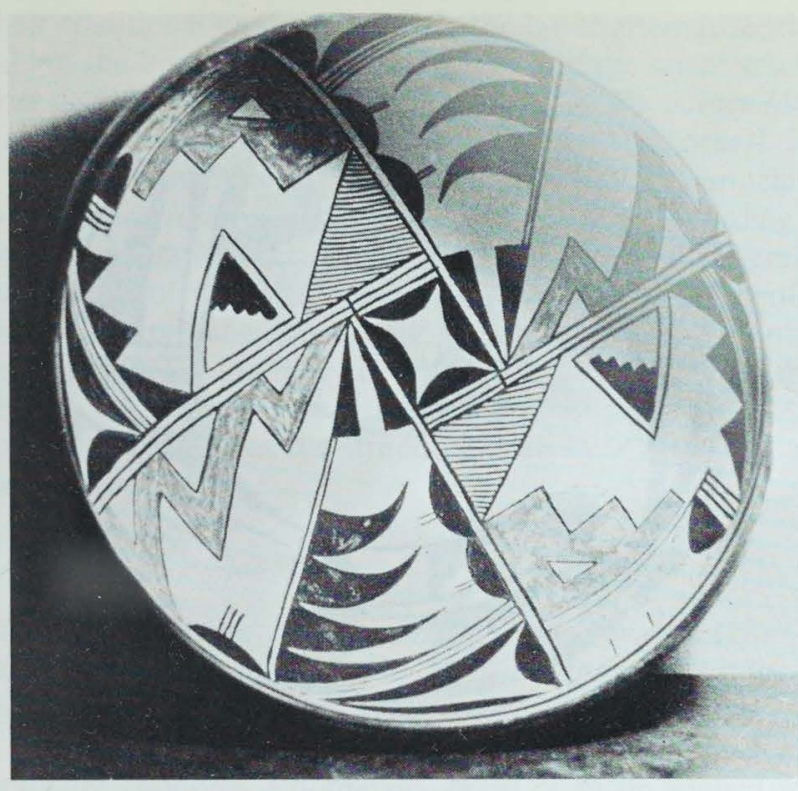

Figure 7

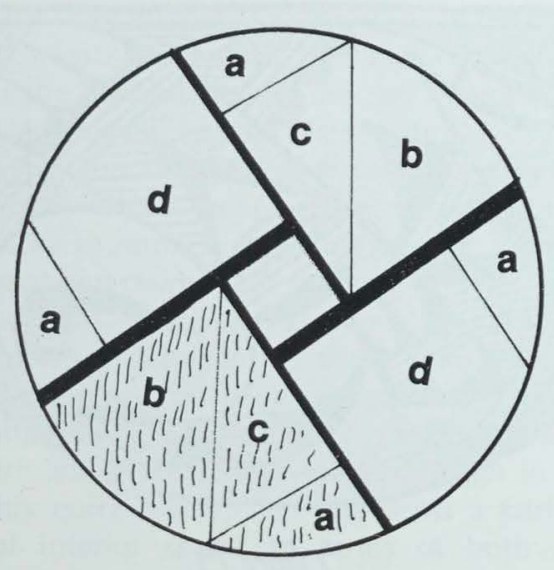

Figure 8

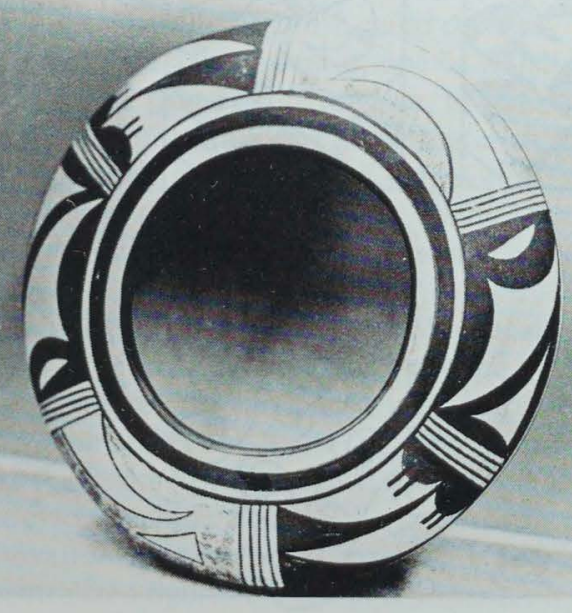

Figure 9

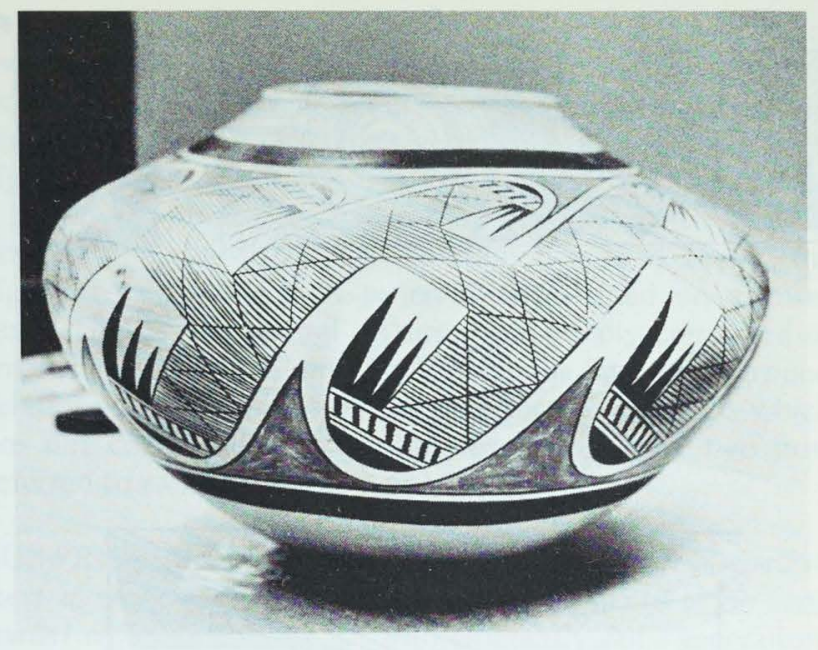

Figure 10
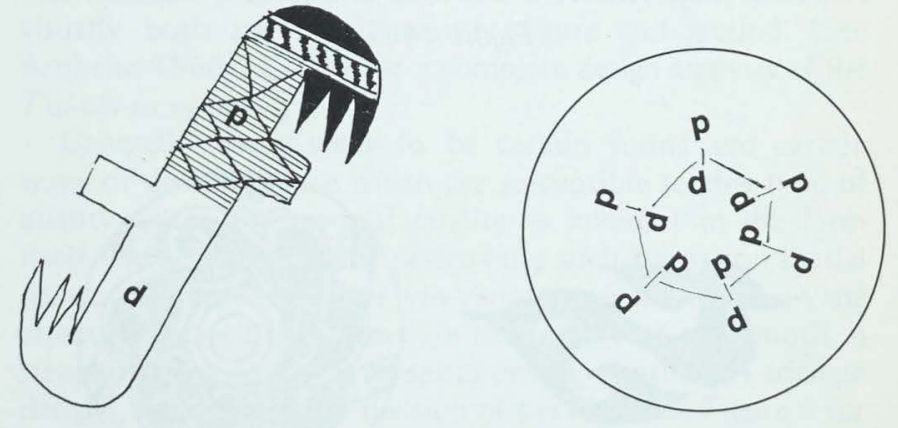

Figure 11

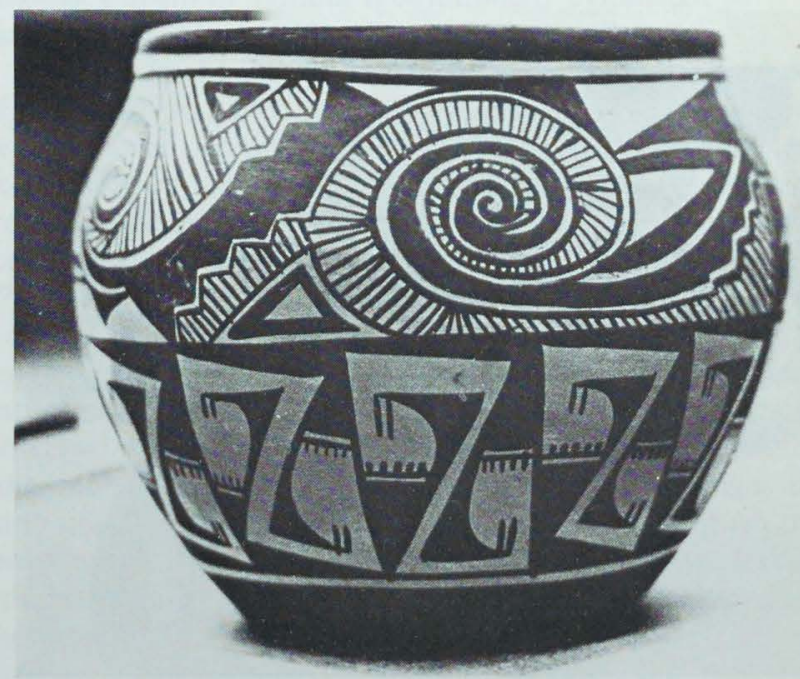

Figure 12 


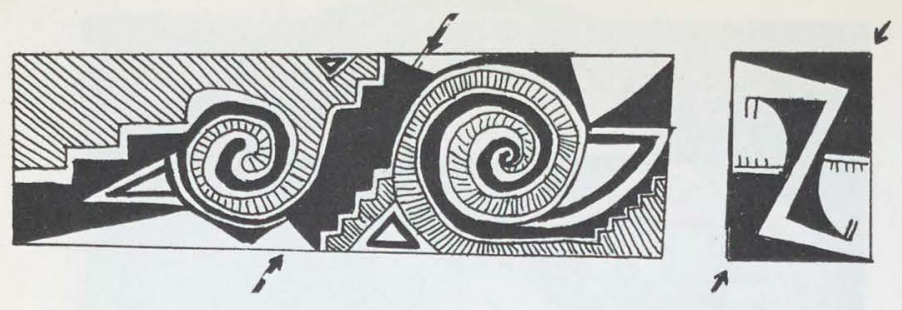

Figure 13
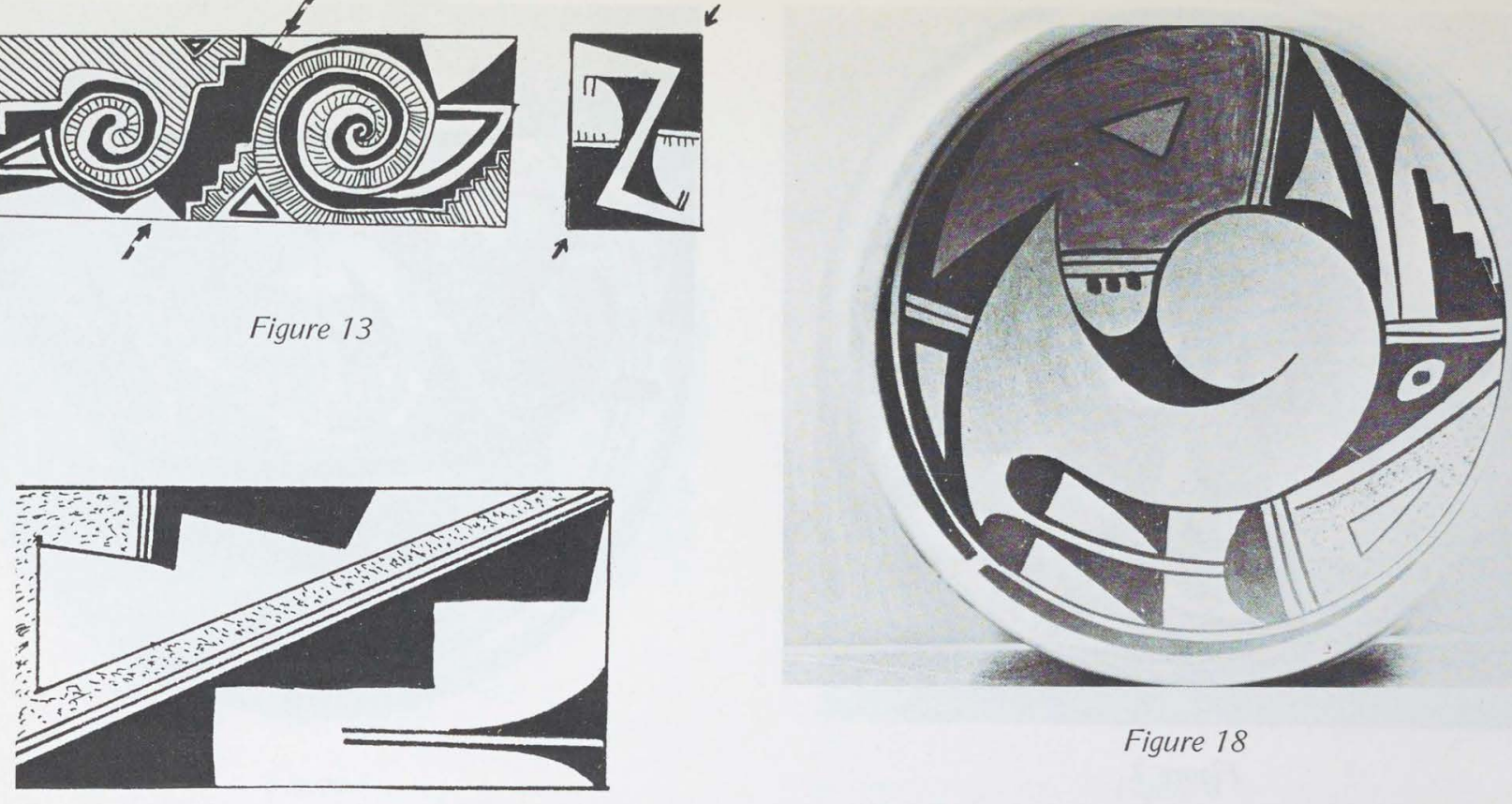

Figure 18

Figure 14

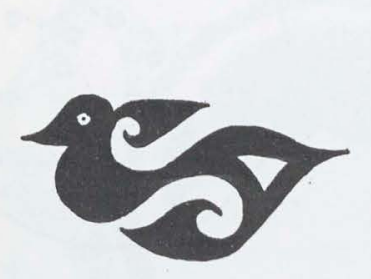

Figure 15

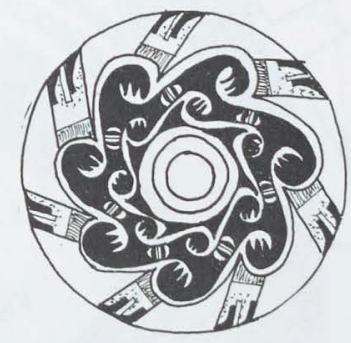

Figure 16

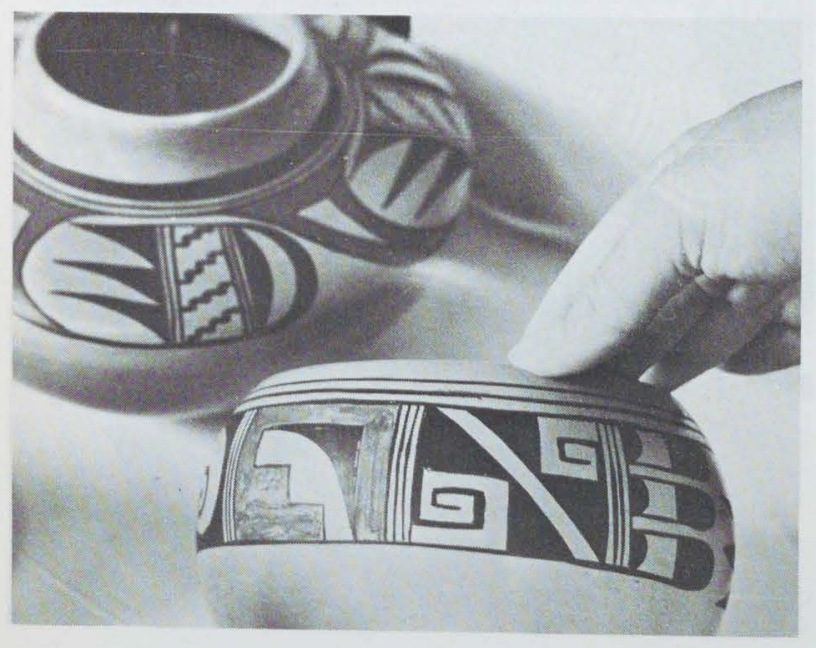

Figure 17
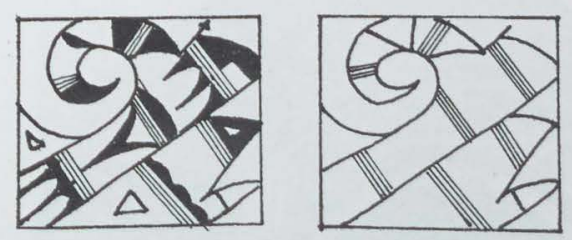

Figure 20

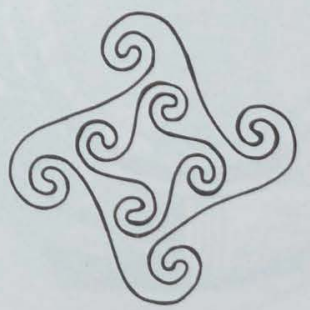

Figure 21

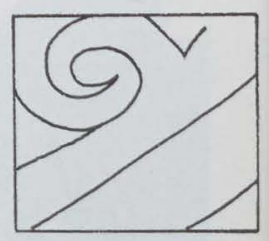

Figure 19

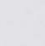

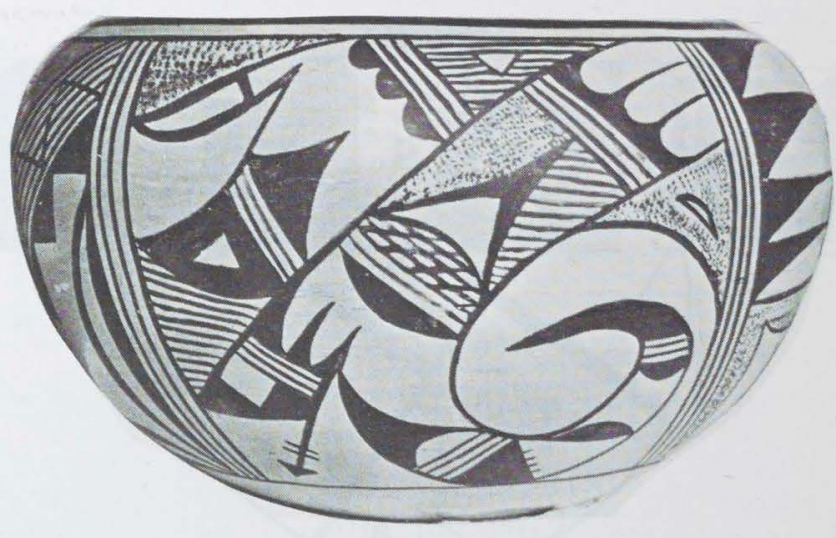


their traditional contexts. I chose the latter alternative, thus taking the bricoleur's way out rather than the scientist's (as that analogy is used in the first chapter of The Savage Mind [1966] to distinguish alternative ways of creating order).

What I have done then is to delineate a series of principles which seem to have generated the designs, or according to which elaboration occurs. When taken together, they create some idea of a design system. The principles are neither linear nor typologically equivalent; rather, they all interrelate. In that sense, they are arbitrarily ordered; and for that reason, I have not numbered them. In that sense also, what follows is $a$ and not the structural analysis of Hopi pottery designs.

\section{Structural Principles}

PRINCIPLE: Designs are formed in such a way that there is equality of figure and ground (to the point of there being no figure and ground).

In our standard design framework, the term figure normally connotes a dominant image or shape applied to a background. And background (or simply ground) normally connotes that area or space remaining after the main figure or figures have been applied. Occasionally in this framework one hears of "negative elements," in which case one normally assumes that the unpainted areas are the figures in that they are the simpler, more dominant shapes, or the shapes which convey meaning. But this implies the same relationship; it is merely the roles which are reversed. Thus the framework seems inevitably to imply a design situation in which there is dominant shape and residual (or subservient) area.

In Hopi designs, however, the painted areas often seem no more simple or dominant in shape than the unpainted areas. In that sense, the figure and ground often seem of equivalent importance, almost to the point of there being no distinct figure and ground. The interior design in Figure 1 illustrates this quite nicely, and represents a fairly typical treatment of interior space. In terms of both the total composition and the individual panels, the painted and unpainted areas are of equal visual importance.

Another treatment of design space, as suggested earlier, is the exterior semi-bounded design (i.e., bounded only by the "roadline," from which the design emanates). The semibounded design shown in Figure 2 could certainly be thought of as three discrete "avian" figures, one of which is shown in the diagram below (Figure 3). However, in terms of the total composition, the unpainted areas assume a shape which is very similar to some of the painted shapes (for example, the scroll, as well as the enclosed areas at the rim), and the figural areas merge into a repeating pattern which assumes prominence.

All of which is not to imply that there are no central "figures" on Hopi pottery. Although not the most common design form, there are designs which are composed of centralized figures (in the sense of figural representations applied to the center of a design field). These are generally avian figures or kachina figures (the latter probably being a recent innovation for the tourist market). However, the existence of centralized figures or figurai representations does not negate the figure/ground relations described above. The modern Hopi pot shown in Figure 4 represents an interesting design solution in this respect; for although it is composed of two central bird figures, the unpainted area is far from being background in the conventional sense. The two inner shapes, the heart shape and the concave triangular shape, emerge as figures in their own right.

And for those central, figural designs which do not employ the unusual design solution described above, the figure/ground equality is generally maintained on a lower level. That is, the central "figures" are usually composed of smaller panels which embody ambiguous figure and ground relations. This is also often the case for those designs which are not composed of a central figure (e.g., the two pots referred to earlier, Figures 1 and 2).

SUB-PRINCIPLE: The smallest panels are often divided in such a way as to yield elements susceptible to a yin-yang spatial organization. What I will reluctantly call a generalized yin-yang model, for lack of a better term, is a more specific and literal form of equal figure and ground than that detailed in the previous principle. In the original Chinese T'ai-chi-tu symbol (popularly known as the yin-yang symbol or still more colloquially as the "yin-yang"), the field is divided into two identical shapes, one dark and the other !ight, such that visually both are simultaneously figure and ground. (See Arnheim 1966:222-244 for a complete design analysis of the T'ai-chi-tu symbol.)

Generally there seem to be certain forms and certain ways of dividing space which are susceptible to this type of duality, since the reversal quality is inherent in the form itself. Many Hopi pottery designs use such forms and spatial divisions to produce near yin-yang or generalized yin-yang effects. Among these forms are the feather or wing motif, a stepped design, a scroll or spiral design, continuous triangle designs, and the oblique division of the field (see Figure 5 for examples).

\section{PRINCIPLE: Designs are often generated by rotation.}

The yin-yang relationship described above can be thought of as having a particular figure/ground relationship. But it has other defining characteristics as well. In particular, the original T'ai-chi-tu symbol is rotationally symmetric or is at least a variant of a rotationally symmetric design.

As the name would imply, rotational symmetry is a form of symmetry in which parts of the design recur as a result of being rotated around a central axis. (For an excellent explanation of rotational and other symmetries, all of which are described and analyzed in terms of the type of operations according to which repetitions occur, see Shepard 1956:267-276. $)^{5}$

The pattern on the canteen shown in Figure 6 is an example of a pattern which appears deceptively complex until one looks at it as a relatively simple rotational design with two equivalent parts in rotational opposition to each other along a central axis. Such bifold rotational designs are fairly common in Hopi pottery. Any line cutting through the center of the field would result in two identical design halves, although clearly the explicit line provides the most obvious division.

Conceptually similar, although more complex than the canteen design, is the design shown on the pot in Figure 7. The same rotational operation is used or implied, only in this 
case there is a fourfold field, with explicit divisions. In addition, the four quadrants have each been further subdivided, such that diagonal quadrants are identical (see schematic drawing, Figure 8). Again, once one perceives the order, the design appears simpler. The rotational symmetry is evidenced in the fact that any line cutting through the center of the field would result in two identical halves.

A common design organization in Hopi pottery is a bounded panel design (with one "horizontal" band which often is sub-divided into repeating "vertical" panels). This format is used both along exterior sides and interior rims. Although the exact number of panels seems to vary considerably, the repetitions seem invariably to occur by rotation or to result in a rotational design. This is evidenced in the relative orientation of the panels, and in their order; i.e., the panels repeat sequentially in a $360^{\circ}$ path. The bowl shown in Figure 9 has a six panel design of this type (consisting of three panels, each of which repeats).

Another common design treatment is exemplified by the pot shown in Figure 10. This is a fairly characteristic Nampeyo pot (cf. pp. 00-00). In this case, there is no explicit division into parts which are rotationally symmetric, but the total is, nevertheless implicitly generated by rotation. In fact, it seems to be generated by two separate series of rotations; i.e., one could think of this design as consisting of one rotational opposition $P_{d}$ which is itself rotated around the center of the pot, thus producing a $P_{d} P_{d} P_{d}$ pattern (see Figure 11).

The reason I earlier detached the rotational principle from the term rotational symmetry is that the phenomenon of rotation can occur without necessarily producing a design which is rotationally symmetric. That is, parts of a design may be in rotational relationship to each other, but those parts may not be identical to each other. Thus, while a given design may not be rotationally symmetric, it may appear less chaotic and more comprehensible when looked at with rotation in mind. The design on the pot shown in Figure 12 represents a case in point. The design consists of two distinct "horizontal" or circumferential bands. The upper band consists of two similar panels (although only part of one panel is shown in the photograph), while the lower band is filled by a series of panels which, taken together, form a continuous design similar to the $P_{d} P_{d}$ design in the previous pot. While not rotationally symmetric (because the two oblique halves are not identical), the panel (drawn in Figure 13) makes more sense if seen as largely influenced by rotation, as the spiral patterns are in a $180^{\circ}$ rotational relationship along the axis indicated. Similarly each of the sub-panels filling the lower band exhibits bifold rotational symmetry along the axis indicated (or, for that matter, along any axis going through the center of the sub-panel).

I could give several other examples of this kind; I will limit myself to just two. The design panel drawn below (Figure 14) is one of many versions of a Zuni-derived panel which is used on both interior and exterior band designs. This design, incidentally, is the "prayer-stick" design mentioned earlier. Although it may appear less obvious (because we are probably not accustomed to considering painted and unpainted areas as equivalent), rotation can be seen to be operative in this case as well. That is, the light (unpainted) "step" figure and the dark (painted) "step" figure are in rotational opposition along an oblique dividing axis. The analysis of this design in this way is made more plausible by the fact that the explicit oblique division of panels into two identical parts is common.

Another version of this same phenomenon can be seen in the drawing below (Figure 15) which represents a central avian figure copied from the interior of a shallow bowl. If looked at solely in terms of the painted areas, the design does not seem to be even marginally rotational. However, the unpainted swirls which are "negatively" defined by the darkened areas can be seen to be in rotational opposition. (While I would not maintain that this was consciously rendered in this way, I would suggest that this is at least an unconscious factor in the aesthetic appeal of this design.) This design, incidentally, is probably derived from a Zuni design as there are similar designs to which it bears some resemblance (cf. Sides 1966, Pl. 17).

Rotation is also sometimes operative in the smallest details and sub-panels. Thus, for example, although the design on the modern pot shown in Figure 1 is not (on the total level) a rotational design, at least one of the panels can be seen to be rotationally generated. I am referring to the crescent panel at the top, which seems to have been treated rotationally even though the shape of the field mitigated against a strict rotational design.

PRINCIPLE: Designs are generated by repetition of elements or by formation of identical elements, and are periodic.

In all of the previously mentioned rotational designs, rotation is the cognitive operation by which repetition occurs. By contrast, bilateral symmetry entails reflection as a way of achieving repetition, and is also used (e.g., Figure 4), but not to the same extent.

The periodicity of the design results from the order and type of repetition. For example, circumferential bands (either exterior or interior to the pot) are composed of panels which repeat in a variety of ways. The panels of these bands can be arranged in a simple repeating pattern $(\mathrm{AAA} \ldots)$ or in an alternating pattern of some sort $A B A B A B \ldots$, or $A B C A B C \ldots)$, or in some cases in an alternating fixed and variable pattern $\left(A B^{\prime} A B^{\prime \prime} A B^{\prime \prime \prime}\right)$. Nonbounded designs such as the one shown in Figure 10 also exhibit varying types of periodicity, depending on the number and type of rotations.

PRINCIPLE: Designs are generated relative to the conceptual center of the field, although this center is not generally made explicit.

In part this is a necessary result of rotation, and in part rotation is itself subsumed by this quality of conceptual center. Any rotational design is produced by rotating certain forms or elements around a center, or by dividing the field in such a way as to produce rotationally related areas. In either case, rotational designs are generated relative to the center of the field.

In previous sections I have made reference to "horizontal" bands, often with "vertical" divisions, although these terms have not always been gravitationally correct; in this respect I have been following Bunzel's interpretive terminology $(1929: 16,18)$. If such bands were simply horizontal (concep- 
tually), they would be generated by sheer repetition of elements or panels along a straight line; that particular design operation has been termed translation by Shepard (1956:269). On a cylindrical surface, such as the outside of a water jug or bowl, such an operation would result in a circular or circumferential pattern (in the same way that maintaining a straight linear path on earth would eventually define a circular path). However, if the band designs were not so much "horizontal" as conceptually circular or circumferential, then they would be conceptually governed by rotation around a central point. Thus the same concrete designs could have been conceptually produced in two distinctly different ways. I suggest that the central point or circumferential interpretation is the more probable one, although I do not think that the two are necessarily mutually exclusive. That is, thinking of the designs as being conceptually generated relative to the center of the field does not necessarily eliminate the possibility of the bands being conceptually "horizontal" as well. My reasons for suggesting a central orientation follow.

First, in many cases there is a similarity between interior designs which are clearly circular in conception, and exterior, "horizontal" or circumferential patterns. For example, the Nampeyo pot shown in Figure 10 has an exterior design which is very similar to an interior design on another Nampeyo pot. I do not have a photograph of this second pot, but the design, which exhibits a definite circular orientation, is shown in schematic form in the diagram below (Figure 16). Thus both would seem to be circular in conception. (Note, incidentally, that the painted spiralling feather patterns are almost identical to the unpainted spiral forms surrounding them, although having an opposite directional orientation.)

Similarly, exterior designs of the type shown on the pot in the foreground in Figure 17 are conceptually similar to interior designs of the type shown in Figure 18. Both are semi-bounded avian designs, emanating from the "roadline." Only in one case the design is an exterior design and in the other an interior design. The conceptual equivalences in other respects suggest that both are conceptually contained in a circular field defined by the "roadline."

Placement of the "roadline" is the most constant and the first operation in Pueblo pottery design (Bunzel 1929:13, 28), and as such seems to represent an initial circumferential definition of the field. Most "roadlines" have a small gap or token non-enclosure, a Zuni practice which the Hopi have adopted. Although the meaning of this conventionalized gap has occasioned considerable dispute (cf. Chapman 1951), the explanation given by Bunzel is that the "roadline" is identified with the life of the potter, and should therefore not be finished. Finishing the "roadline" is symbolically equated with ending the potter's life (Bunzel 1929:69), and thus entails completing a circle or a full cycle.

Many designs can be seen to emanate from the "roadline," often spiralling in toward the center of the design (see, for example, the design just mentioned, viz., Figure 18). This central orientation is somewhat apparent in the design product. In addition, the indication of movement inward toward the center has at least been mentioned, if not fully and elaborately documented, in the literature. Thompson (1945:550) reports that designs move in a circle and toward the center in a circular and centripetal movement. Ortiz
(1972:143) reports that in sand painting, one of the most sacred acts performed in the society, the outer boundaries are first set, and then the painter works inward toward the center of the field.

Lastly, evidence for the central orientation of designs is suggested by the common use of bifold, fourfold, and other rotational symmetries, as well as rotationally-derived panel designs. All of these are either a result of, or imply, rotation around a center or central point.

Thus the center of the field is vital as an organizational or implied force or locus, rather than as an objective or explicit form or point. In Western art, by contrast, the center of the composition is generally filled, although it may not exert any particular force on the rest of the composition.

PRINCIPLE: The elements in Hopi pottery designs often seem to be generated by division of the field; i.e., elaboration of design occurs through division into elements, rather than by the cumulative addition of elements.

Although my first inclination in studying Hopi pottery had been to (1) isolate elements, and (2) then determine how they were combined, this procedure was discarded because following it seemed to make the designs more rather than less confusing. It seemed that the elements were often derived from the designs rather than vice versa; that is, the elements seemed, in many cases, "emergent" rather than basic.

For example, the design on the modern pot shown in Figure 19 (which is a four-panel design) appears to be a rather chaotic design, which maintains its chaotic appearance so long as one tries to conceptualize it by pulling out elements one by one (particularly since one runs into immediate figure/ground problems in even trying to decide what the elements are). However, if one conceives of the design as generated by progressive divisions or setting of boundaries with the filling in of details (thus creating elements as the last step), it becomes more visually comprehensible. The schematic diagram below (Figure 20) represents one possible reconstruction of one of the panels. Unfortunately I did not witness the actual painting of the design diagrammed in Figure 20, nor was I able to interview the potter, so my reconstruction is admittedly speculative. More important than the specific sequence of the divisions, however, is the idea of progressive divisions and emergent elements. And for this general idea there is additional evidence, both material and textual.

First, the visible intersections and overlappings of lines on the pots themselves can provide some information as to sequence by which the designs were created; and secondly, what descriptions there were of the decorating process seemed supportive. For example:

\footnotetext{
The area to be decorated is usually bordered or circumscribed by several parallel lines or bands. Then the area is divided into two or more units and next the larger design elements are applied. Areas which are to become solid masses of color are first outlined and then filled in. Thus the design progresses from the larger, simpler masses and lines to the more intricate details. One unit of the design is not completed until the next unit is started. The units are considered in their relation to each other and are developed alternately [Hubert 1937:9].
}

I do not mean to imply, by any of the above, that elements do not exist in Hopi pottery designs. Nor do I mean 
to denigrate attempts to isolate and name motifs, although Bunzel did meet with somewhat limited success in that particular endeavor (1929:53-54, 70, 118-119). Rather, I am suggesting that the procedure of isolating and classifying design "elements" per se without considering how these were themselves derived, is of dubious utility in the context of Hopi pottery.

As it happens, that very procedure has been followed in at least one case of which I am aware. In a study of Hopi pottery exhibited at a 1959 Museum of Northern Arizona craft show, Sikorski (1968) has isolated, and classified Hopi elements. The study includes a page of over one hundred diagrammed "design elements" arranged in six categories, e.g., "triangle," "curved elements," and "irregular elements" (1968:18). Not only do several of the elements seem to have been arbitrarily assigned to one category as opposed to another; the rationale for isolating and defining certain configurations (many of which are irregular) as entities or elements is neither self-evident nor explained. In total, this classification and isolation of "elements" does not seem to clarify anything. However, this very lack of clarification may be, itself, revealing.

PRINCIPLE: Lines are more nearly devices for defining boundaries, areas or movement, than themselves elements or entities.

The phenomenon of generation of elements by division and later filling in of areas is apparent on other than totally bounded panel designs of the type shown earlier (Figure 19). In part, this is the case because so many of the unbounded designs are composed of panels at the lowest levels (e.g., the pots shown in Figures 2 and 4 ). However, it is also often evident on those pots whose designs are not composed of panels or sub-panels at the lowest level. The Nampeyo pot (Figure 10) is such a pot; rather than being produced by the cumulative addition of given elements, the design seems more nearly to have been generated by lines which reflect paths of motion (thus creating areas which are filled in or elaborated with hatchure). All of which could be stated in the form of the above principle.

PRINCIPLE: The design field is not uniformly elaborated, nor is balance literal.

This is a negatively significant principle. It is probably related to equality of figure and ground, and is in that sense stating the antithesis of the principle or phenomenon which has been termed horror vacui or aversion to unfilled space in reference to art styles such as that of the Northwest Coast or Maori art. Since non-painted space seems to have value (cf. pages 00-00), there would seem to be no need to achieve balance through uniform filling of the field.

PRINCIPLE: Color does not seem to be employed to distinguish between dominant and subsidiary elements or areas, although it is used differentially for lines versus areas.

Again, this is a negative principle, and again it is stated to contrast Hopi designs with other two- or three-color design systems (such as the Northwest Coast system which uses what have been designated primary, secondary, and tertiary color systems [Holm 1965:29-32]). Unfortunately, none of my photographs or drawings are in color, so it is difficult if not impossible for the reader to determine the colors in the pots illustrated here. All of the pots shown here are painted in dark brown or black, and most use in addition, a dark red or reddish brown pigment. (Also common, though not shown here, are pots with a red slip with dark applied designs, or with a more yellowed slip.) With one or two exceptions, none of which are shown here, the lines seem always to be applied in the dark black-brown pigment, with the reddish pigment applied only to fill in areas. The largest painted areas, in particular, seemed to have been filled in with red, so as to avoid too black a design.

\section{Structural System}

Having delineated several inter-related structural principles in what I have called "bricoleur's terms," I would like to pull these together into a more integrated and explicitly defined system especially since many of the principles, when taken together, suggest additional or emergent aspects of the Hopi pottery design system.

Rotation versus bilaterality, as used here, are not merely terms for describing relationships between elements once a design is produced; rather they describe the forces or operations by which the designs are produced. Moreover, the use of each seems to imply certain concomitant relationships. In particular, the general tendency to favor rotational over bilateral symmetry has the following implications: (1) it tends to produce a dynamic rather than a static design; (2) it implies a design situation in which only one element is repeated, whereas bilateral symmetry often requires two different forms of the same element (equivalent to a right-hand and a left-hand form); and (3) it suggests the importance of a conceptual center (often non-explicit) which is the one constant point in the $360^{\circ}$ rotation of a central axis, or is alternatively the intersection point of all central axes. Further, all of the above implications are reinforced by other individual design principles or characteristics, as these have been delineated earlier.

Thus, for example, the dynamic rather than static quality of the design system is reinforced by figure/ground reversals and equivalences (particularly those which follow a generalized yin-yang model), by the oblique division of panels (which suggests rotation), by the use of obliquely placed lines to define areas which are in rotational opposition to each other, by the use of tapering shapes and areas (which suggest transition), and by the use of spirals and other directional elements rather than more static and stable rectangular elements. All of the above tend to imply transition or movement and are in that sense dynamic visual devices or arrangements. In addition, the general dynamic aspect of the design system is specifically cyclical and periodic. This cyclicity and periodicity are emergent both from rotations (as are implied in the Nampeyo design shown in Figure 10 and diagrammed in Figure 11), and from sequential repetitions of the type which occur in the $\mathrm{ABABAB}$ or $\mathrm{ABCABC}$ type of bounded panel designs (cf. Figure 9).

The single rotated form versus the mirror-image forms (i.e., left-hand and right-hand forms) similarly relate back to the total system, particularly to figure/ground reversals. Both bilateral and rotational symmetry could be considered as 
visual representations of duality; yet the types of duality represented would differ. In the rotational case, since the forms are identical (at least in terms of shape), the opposition is totally based on position or relative location. In the bilateral case, by contrast, which uses mirror-image forms, the opposition is based on opposite forms or entities. One might think of rotational symmetry as $x$ and complement of $x$ (at least in a yin-yang model), and of bilateral symmetry as $x$ and anti-x. The yin-yang form, as described earlier, is that specific form of bifold rotational symmetry which uses forms of identical shape but different color. As employed in Hopi pottery designs, the yin-yang model produces a situation in which one form is explicit (i.e., painted), whereas the other is implicit (i.e., itself unpainted but defined by the surrounding painted areas) (cf. Figure 5). The resulting duality exhibits complementary opposition. The interior Nampeyo design drawn in Figure 16 is interesting in this respect in that, at the total level, the pattern exhibits a duality of the complementary, implicit versus explicit variety. The painted and unpainted areas are each other's complements in terms of shape, although the orientation and implied directional movement are diametrically opposed. Complementary duality of this sort is related both to figure/ground equivalences and to the use of rotational symmetry.

Another characteristic of the total design system which is emergent from the several individual design principles, when these are considered together, is the importance of the total design as a total design. That is, the designs seem to be generated from the highest level downward, rather than being built up from a series of discrete elements. The distinction which I am trying to make here is analogous to the difference between a logical system which is based on deduction and one which is based on induction. In part, the importance of the total is evidenced in (or resultant from) the generation of designs relative to the conceptual center of the field. But more importantly, it is evidenced in the progressive divisions of the field such that elements are seemingly the conceptually last phase in the generation of the pattern rather than the reverse, i.e., the generation of pattern by the cumulative addition of elements.

The above point is important, if for no other reason than that it runs counter to the "natural" assumption that elements are of prime importance, with operations being defined in terms of elements, and being significant only as they specify the ways in which elements are to be combined. Such an assumption could follow quite automatically from an attempt to translate or adapt linguistic methodology directly to the visual realm. In the Hopi case, it would seem that operations have primacy. Moreover, operations seem to be performed relative to the total. Thus, for example, in the course of this structural analysis, it often seemed more accurate to suggest that a field was divided in order to produce $x$ number of panels rather than to say that a particular panel was repeated $x$ number of times (e.g., Figure 9), or to suggest that a field was divided in such a way as to produce four quadrants in rotational opposition to each other, rather than to say that a section was repeated four times (e.g., Figures 7 and 8 ).

Finally, the Hopi design system seems to be composed of different levels of design, all working in similar ways, rather than being based on dominant and subservient (or filler) elements. This is due to the importance of the total design and its central orientation, the emergent aspect of elements, and the primacy of operations over elements. Thus, for example, the total design may be composed of several panels, which are in turn composed of sub-panels, which are further divided and filled, etc.

\section{STRUCTURAL SIMILARITIES IN OTHER SYSTEMS: WORLD VIEW}

The premises of this study, it should be recalled, are twofold: (1) that designs can be analyzed as a structural system, i.e., that certain generating or structuring principles can be inferred by induction, and (2) that the structure of designs should logically be related to the structure or structuring of other Hopi cultural systems. Thus, having attempted a "structural analysis" of Hopi pottery designs and having arrived at a particular visual structural system, an obvious second step would be to see if, or rather how, these visual structures correlate with the structure of other systems. For example, does the way in which the designs are organized have anything in common with the way the Hopi cosmos is conceptually organized (or structured)? Or, more realistically, what do the two systems have in common? Although any number of Hopi systems and sub-systems could have been analyzed for purposes of comparison, the "world view" or structuring of world seemed the most basic, and therefore the most obvious system to present in the brief space allotted here.

\section{"Linguistic" Structuring of Reality}

The choice of world view was a particularly obvious one since it was largely on the basis of Whorf's studies of Hopi linguistics $(1936,1938,1940,1941)$ that he formulated his noted hypothesis, and since I am considering "world view" or cosmological organization broadly enough to incorporate Whorf's lexical and grammatical structuring of reality, i.e.:

A world view provides a people with a structure of reality; it defines, classifies, and orders the "really real" in the universe, in their world, and in their society. In Clifford Geertz's phrase (1957), a world view "embodies man's most general conceptions of order" [Ortiz 1972:136].

According to Whorf (1950:68), the metaphysics underlying our own language entails the imposition on the universe of two grand cosmic forms: time and space. The former is kinetic, one-dimensional, and subject to a threefold division, i.e., past, present, and future; the latter is static, threedimensional, and consists of infinite space.

By contrast, time and space, as such, are simply not Hopi concepts. That is, time as an objectified concept is not translatable into Hopi, either in terms of specific words, expressions, grammatical forms or constructions; nor do the tenses past, present, and future have Hopi equivalents (Whorf 1950:67). And yet, as Whorf points out, without these distinctions "the Hopi postulates equally account for all phenomena and their interrelations" (1950:67). The question is, how? The answer is that the Hopi also impose upon the universe two grand cosmic forms: these are not 
time and space, but rather manifested and unmanifested (or manifesting). These could also be thought of as objective and subjective:

The objective or manifested comprises all that is or has been accessible to the senses, the historical physical universe, in fact, with no attempt to distinguish between present and past, but excluding everything that we call future, BUT NOT MERELY THIS; it includes indistinguishably all that we call mentaleverything that appears or exists in the mind ... and by an implication and extension... in the very heart of the Cosmos itself [Whorf 1950:68-69]

Whorf makes the observation that $w^{6}$ carry spatial concepts (almost obsessively) into our speech and thought through the use of spatial metaphors of all sorts, and by "objectifying-imaginatively spatializing qualities and potentials that are quite non-spatial (so far as any spatiallyperceptive senses can tell us)" (1941:83). By contrast, the Hopi language evidences a total avoidance of such metaphors and extensions of spatial concepts to non-spatial matters (1941:83). Whorf's explanation for this phenomenon is that major Hopi grammatical patterns do not provide analogies for imaginary space, and that the Hopi have other linguistic devices, in particular verb forms, which serve the same expressive purpose (Whorf 1941:83).

Rather than suggest that the Hopi do not carry spatial concepts into their language and thought, as Whorf does (1941:83), I suggest that one could as validly say that the Hopi carry "non-spatial" concepts into their spatial thought. That is, that the same structuring principles come through in verbal and visual thought and expression.

For example, it seems that sequence, repetition, duration, and intensity in the Hopi language are all relevant considerations in Hopi designs and express characteristics which were seen to generate the designs.

The more one learns about Hopi linguistic forms, the more apparent the parallels between linguistic forms (particularly verb forms) and the structure of the design system become. For example, in a quite detailed paper, Whorf (1936) deals specifically with two of the nine aspects of Hopi verbs; the segmentative and the punctual. In that paper he presents the following series of concrete examples to demonstrate the change from a punctual aspect (manifested about a point) to a segmentative aspect (a series of repeated interconnected segments of one large phenomenon), by the consistent reduplication of the root and addition of a suffix (Whorf 1936:52): ha'ri it is bent in a round-
ed angle

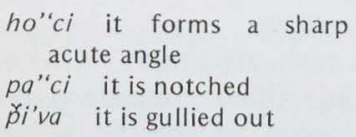

ca'mi it is slashed inward from the edge

$$
\begin{aligned}
& \text { hari'rita it lies in a mean- } \\
& \text { dering line, making suc- } \\
& \text { cessive rounded angles } \\
& \text { (applied for instance to } \\
& \text { meander patterns in } \\
& \text { decoration) } \\
& \text { hoci'cita it is zigzag } \\
& \text { paci'cita, it is serrated } \\
& \text { piva'vata it extends in suc- } \\
& \text { cessive gullies and } \\
& \text { gulches (said of ground) } \\
& \text { cami'mita it is fringed, it } \\
& \text { is slashed into a fringe } \\
& \text { along the edge }
\end{aligned}
$$

What is significant in terms of this paper is neither the specific linguistic mechanism used (although it relies on a reduplication which is interesting), nor the specific Hopi words, but rather both that the specific connotations of the above words (punctual and segmentative) seem eminently suited to describing many Hopi designs, and that the implied cognitive distinctions which are apparently necessary in choosing the proper aspect of a verb also seem relevant to Hopi designs. Moreover, the particular set of words cited above is not unusual in terms of the particular discriminations which it requires.

The Hopi language is equipped to deal with (and requires discriminations dealing with) vibratory phenomena, forces, repetitions, type of sequences, duration, etc. Similarly, the design system seems to be based on repetition, to be generated by central forces and by rotational forces and movements, and to vary according to number and type of sequences. In addition, the Hopi language exhibits marked tendencies to use verbs rather than nouns (Whorf 1950), to transform our propositions about things into propositions about events, and not to "objectify" or think in terms of entities (Whorf 1941:79). I cannot over-emphasize that processual descriptions based on operational distinctions of the above type seem more readily applicable to a description of Hopi pottery designs than a terminological system based on classifications of elements or "entities." It is relatively easy to determine sequence, repetition, and intensity of designs (which areas are highly developed and which are not); it is not always possible to determine which parts of a design are object (figure) and which are ground. It is also interesting to note that, as a specific alternative to "objectifying" things (thus creating "entities" of such "things" as days and hours) and creating imaginary plurals on these "entities," the Hopi language relies instead on cyclicity and patterns of repetition (Whorf 1941:78). Their designs also seem to be based on cyclicity, and patterns of repetition, to the point of reflecting patterns of change without having discrete "elements" (e.g., Figure 10). As for the two grand cosmic forms which Whorf (1950:68) has delineated-manifested and unmanifested-it seems more than coincidental that there is not a figure (object) on a (residual) ground in Hopi pottery designs, so much as an explicit or painted form and an implicit or unpainted form, each of which seems significant (cf., in particular, Figure 16). Could this not be seen as a visual representation or rather a structural reduplication of "the Hopi philosophy of the universe in respect to its grand dualism of objective and subjective" (Whorf 1950:70)? I suggest that, if not created with this similarity in mind, the designs which employ this device are unconsciously appealing, or correct, or "aesthetic" because of this structural similarity.

\section{Cosmological Structuring and Reality}

While the preceding Whorfian analysis presented a way of "structuring reality," and could in that sense be considered a "world view," it was so abstracted as to be more of a meta-world view. I would therefore like to use this section to briefly present a more specific, or at least more concrete version of the Hopi world view, particularly the Hopi cosmology, which could perhaps be thought of as a created rather than a mediated reality. Toward this end, I will rely heavily on overview articles by Ortiz (1972) and by Thompson (1945). 
Ortiz (1972) concedes that it is both possible and productive to talk of a general Pueblo world view, i.e., those aspects of world view which are universal to all the Pueblo people (1972:142). The first generalization which he proposes for all the pueblos is that:

they all set careful limits to the boundaries of their world and order everything within it. These boundaries are not the same, but, more important, the principles of setting boundaries are ... [Ortiz 1972:142]

The idea of setting boundaries at all, and further, the idea of setting them as an initial operation in the process of ordering, is once again paralleled in the Hopi design system. Their pottery designs seem, in many cases, both processually (cf. Bunzel 1929 and Hubert 1937:9) and conceptually (cf. the Structural Analysis section of this paper) to be generated by the successive setting of boundaries. I might add, as an aside, that Hopi architectural terminology also deals with boundaries of spaces rather than with spaces as entities (e.g., rooms, hallways, etc.); thus hollow spaces are not named as objects but are rather located or described by relative location (cf. Whorf 1953).

The boundaries of the cosmos are specifically set by the Hopis according to four cardinal directions and three cosmic levels. In addition:

All the Pueblos also have a well-elaborated conception and symbolization of the middle or center of the cosmos, represented by a sipapu, an earth navel, or the entire village. Usually there are many different centers because sacred space can be recreated again and again without ever exhausting its reality.... Among the Pueblos, the center is the point of intersection of the six directions, with a seventh being the center itself. If only four directions are given symbolic elaboration, the center will be the fifth direction [Ortiz 1972:142].

The importance of a conceptual center as a generating force, and indeed as the intersection point of several directions, again seems structurally congruent with the conceptual importance of the center as a generating force in the design system. In that system, the center is the intersection of all central axes, or the constant point in the rotation of any one axis. Similarly, the relative definition of sacred space seems to be structurally duplicated in the individual design panels and sub-panels which are organized (rotationally or otherwise) relative to their own respective centers.

Much of what I have discussed previously is corroborated by Thompson $(1944,1945)$, such as: the tendency to conceptualize phenomena in terms of growth cycles, repetitive and vibratory movement patterns and serial metamorphoses, the tendency to conceptualize Hopi history as an unfolding of sequences or phases, and the dynamic view of the cosmos (1945:542). The nature of Hopi duality, particularly as that duality differs from our own, is also discussed:

the Hopi concept of the balanced, correlative interdependence of the manifold aspects of reality excludes an arbitrary over-all dual division, such as that which structures our own thinking and forms the basis for our traditional ethical concept of the competing forces of good and evil. Duality in the Hopi world view exists only insofar as it represents two correlates in a reciprocally balanced universal scheme, and each correlate is conceived as an indispensable part of the whole, neither one being essentially subordinate to the other [Thompson and Joseph 1944:44].
At the risk of belaboring a point, I suggest that the type of duality described above is structurally duplicated in the yin-yang type of (complementary) duality which is based on equal figure and ground and on rotational symmetry, rather than in the (antithetical) duality of bilateral symmetry.

Once again, the importance of the total, and of periodicities and cycles, suggests apparent structural parallels with the design system. In particular I suggest that such designs as the pottery design shown in Figure 10 (and schematically diagrammed in Figure 11) represent a visual structural replication of the way reality is conceived, again probably unconsciously. I further suggest that structural parallels are to be found and are significant in other systems, e.g., Hopi ethics or Hopi religion, but shall not deal with these at this time. The world view has already been discussed in sufficient detail to at least indicate the plausibility of the structural analysis of pottery designs given earlier in the Structural Analysis section and to suggest that that structural system relates to other "non-visual" structures and structurings.

\section{CONCLUSIONS}

In an effort to elucidate the elusive nature of structure, Lévi-Strauss (1960:52) made reference to a hypothetical jig-saw puzzle generated by a hypothetical mechanical saw, the movements of which were regularly modified by a hypothetical cam shaft. The structure of the puzzle does not exist, he suggests, "at the empirical level" (which would, I presume, be essentially a description of the proxemic relationships between parts of the assembled puzzle); rather, it lies in the mathematical formula which expresses the shape of the cams and their speed of rotation.

With the frank acknowledgment that I will in the process probably be subverting the intended meaning of Lévi-Strauss' analogy, I would like to extend it. I suggest that the above formulation "of the empirical level" could be thought of as structure (noun form), whereas the mathematical formula would, by contrast, represent structure (verb form). The former refers to product; the latter refers to process. Similarly, I suggest that designs could be thought of in terms of design (noun form) or in terms of design (verb form).

This paper represents an attempt to deal with design (verb form), with design as process, with design as a created system which follows certain principles of elaboration which may well conform to the principles followed in other cultural systems. In that context, my main conclusion is that I have begun, and that that beginning is worth continuing. In that sense, the questions I have answered, however tentatively or speculatively, are less interesting than the further questions which those tentative answers suggest. Accordingly, my conclusions will deal both with what has actually been done in this study, and with what further studies or approaches could or should, as a result, be attempted.

\section{What Has Been Done in This Study}

Very simply, I have attempted both to delineate the structure of a particular design system, and to compare that structure with the structuring principles followed in other systems in that culture. In particular, I have dealt with 
linguistic structuring of reality, since much of Whorf's work was with the Hopi language, and since I was initially interested in a visual equivalent of the Whorf Hypothesis. The tentative conclusion on this particular relationship is that the same structuring principles do seem to be operative in both systems, and in other systems as well (cf. Thompson 1945; Ortiz 1972). A further conclusion, which will be elaborated below, is that such structural similarities are revealing.

In terms of the specific structural analysis of Hopi pottery designs, certain tentative conclusions are more intrinsically interesting than others. In particular, I am thinking of my tentative conclusions as to: (1) the importance of operations rather than entities as a conceptual clue to the organization of the designs, and (2) the likelihood of designs being generated "downward" by successive divisions rather than "upward" by the cumulative addition of elements. Both of these are interesting if for no other reason than that it often seems to be assumed that the reverse is the case, i.e., that elements are of prime importance, and that designs are formed by the progressive addition of elements. The point here is that the reverse may be the case in some art systems, but that it needn't necessarily be the case. The seeming lack of figure and ground in the traditional sense is also an interesting principle in this respect; i.e., it is possible not to have traditional (dominant) figures and (residual) ground, as such.

In that sense, my specific analysis of Hopi pottery designs as a structural system serves to expand and explore the realm of logical possibilities of design, so that actual ways of organizing designs can be placed in the context of possible ways of organizing designs. Such an examination of logical possibilities (particularly as these are phrased in terms of structural possibilities) is essential if one is ever to be able to discuss the logical probabilities of designs or design motifs occurring in disparate cultural groups, or if one is to draw cross-cultural comparisons. I suggest that if a cross-cultural grid or etic scale is at all possible, it will ultimately be a structural grid. To the extent that this paper deals with a process approach to art, and attempts to examine structural possibilities and cognitive implications of possibilities, it contributes towards the eventual establishment of such a grid. To the extent that it also seems to make Hopi pottery designs more visually and conceptually comprehensible, it also makes a contribution.

In addition to feeding back into the art context from which it derived, I think this study has a minor, though real, potential for being recycled into the structural framework from which it derived. That is, I think that any information on "visual" cognition and structuring is of obvious relevance to structural theory in general. For example, the distinction between the dualities entailed in rotational versus bilateral symmetry seems to suggest that "binary oppositions" may be of more than one type (e.g., antithetical oppositions and complementary oppositions) and would probably be worth investigating further.

The above are what I consider to be the strengths of this study. However, the study itself suffers from a certain symmetry and balance: every strength is matched by a weakness. Generally the weaknesses seem to follow from the tentativeness of the study. In particular, I see three weak- nesses, none of which are irremediable. (The remedies will be discussed in the next section.)

First, this study would have been infinitely stronger if I had been able to interview potters, and to observe the designs being painted. Instead, I had to rely on written material, and answers to other people's queries (e.g., Bunzel 1929), which did not always correspond to what I would have liked to ask.

Second, the structural analysis of the design system was phrased in such a way as to be more subjective than objective. The analysis was certainly made more plausible by the existence of numerous structural similarities in other systems. However, these similarities present a compelling rather than a conclusive case for the analysis. Thus, although one could argue that the analysis was to some degree confirmed by the structural similarities in other systems, such an argument would be undeniably circular, i.e., preliminary research on the Hopi no doubt influenced the analysis of their pottery. (However, if the argument is circular, it is no more circular than the relationship which is being investigated.) All of which is not to say that an analysis such as was given in the Structural Analysis section must necessarily remain either tentative or unverifiable. Rather, it can be used to generate predictions which would themselves be testable. At least one such set of predictions will be discussed in the next section.

Third, this study suffered from the lack of an adequate terminology with which to describe a design system concretely and precisely, and with which to state empirically verifiable propositions. Having chosen the "bricoleur's out" to describe the structural system, I made no progress in the specific invention of a genuinely "scientific" terminological system. However, the general parameters which such a terminology should follow did become clearer.

\section{What's Being Done as a Result of This Study}

i am currently following two quite distinct lines of investigation, each of which follows from the framework and conclusions of this paper. The first entails making specific experimental predictions on the basis of the Hopi study, and devising a feasible way of testing them. The second entails studying an entirely different art system occurring in a structurally dissimilar though equally cohesive society, in an effort to broaden my framework and test its general applicability and explanatory value. Both will be briefly described below.

Although the specific structural analysis presented in this study is of unverified psychological validity, it can be used to generate predictions which are directly verifiable. Toward this end, I returned to and modified my original idea of test drawings. As conceived of originally, the test drawings would have entailed taking a standard design motif, varying it randomly, and using those variations to determine which types of variation are significant and which are not. Whereas this seems to work well for linguists, and is methodologically flawless, it is quite unwieldy when operationalized for designs because the variation is hard to control. The test drawing technique was eventually modified such that it was not to be used to elicit information randomly, but rather to test specific predictions. 
The experimental procedure is as follows: The subject is given a drawing of a simple design and asked to examine it so that he can subsequently reproduce it from memory. He would then attempt to draw it himself, and would be given the opportunity to make verbal corrections and to indicate possible deficiencies and vagueness in his drawing (thus allowing him to compensate for lack of drawing ability and providing a measure of his certainty as to what was correct and what was hazy in his visual memory). Lastly, he would be asked to describe the original design verbally. The drawing process would be filmed, thus providing a permanent record of the sequence in which the design was reproduced. ${ }^{7}$

The theory behind such a procedure is as follows: First, it is assumed that in order to reproduce the design, the subject would be forced to actively organize it and classify it in a systematic way. The correctly rendered aspects of the design would provide some indication as to which aspects of the design were actively classified and in what ways, just as the mistakes would presumably indicate which aspects of the design were not particularly relevant to the viewer's ordering system. Similarly, it is thought that the sequence in which the design is reproduced is indicative of the relative importance of the various ordering principles. The use of verbal description would provide a way of testing the relationship between linguistic categories and visual discriminations: presumably those aspects of the design which are noted verbally would be correctly rendered in the subject's drawing.

In order to obtain significant results in the above experiment, the test drawings would have to be created with specific ordering principles and variables in mind. For example, see the test drawing below (Figure 21). It is a relatively simple and highly regular design if perceived as a rotational design composed of an inner and outer line arranged in directional opposition to each other. If one were more accustomed to bilateral symmetry, and tended to classify in terms of entities rather than lines, it would probably be considerably more difficult to perceive correctly.

Using such a test drawing, and on the basis of both the structural analysis of Hopi pottery designs and Whorf's work on linguistics, I would make several predictions. Specifically, I would predict that if the above test drawing were given to a large group of Hopis and a large group of Anglo-Americans, the following patterns would emerge statistically: that the Hopis would be more consistently accurate in rendering the rotational repetitions and the specific directions would be more often correctly reproduced, that the Hopis would be more likely to notice that all of the swirls (including the inner ones) are virtually identical in size, and that they would be more likely to reproduce the design by first drawing a continuous outer and then a continuous inner line (rather than by several choppy lines used to block out a shape). I would also predict that the Hopis would be more likely to verbally describe the design in terms of lines and motion, and that the Anglos would be more likely to describe it in terms of entities.

The second line of investigation which follows indirectly from the structural analysis of Hopi pottery designs is an analogous though greatly modified structural study of Northwest Coast Indian art. In part, that particular system interested me because it is structurally opposed to the Hopi system in so many ways: Northwest Coast designs are predominantly bilateral (to the point of split representation), balance is quite literal (e.g., literally an eye for an eye and a tooth for a tooth), the field is almost entirely filled in many cases, and "elements" seem to be extremely important. The organization of Northwest Coast societies seems correspondingly opposed to the Hopi organization as well, but it does not seem worthwhile to develop those comparisons at this time.

In the particular study of Northwest Coast art which I am working on at present, ${ }^{8}$ I have changed my approach in the following ways. First, I am considering operations which are more directly Lévi-Straussian, i.e., (1) the operation of visual intersections, and (2) the operation of inversion. The former operation is visually equivalent to mediation as that is used in myth, and seems to be a reverse and complementary operation to visual opposition. It is used as a way of combining both elements (to produce a formline system) and total figures, and is the specific mechanism by which numerous visual puns are formed. The operation of inversion is used on the meaning level such that humans and crest animals are shown in symbolically inverted circumstances (e.g., a crest animal which occurs on a headdress worn by a chief might itself be wearing a similar headdress consisting of a human figure). Again, the operation is similar to one which occurs in myth. Secondly, I am working on the meaning level more directly, since much of Northwest Coast art is crest art, or is at least directly representational. (The premise in this case is that such an art system is used as much to indicate relationships between crest groups as to merely differentiate them.) What follows directly from the Hopi study, in this case, is the use of a process model which is directed at operations rather than at configurations.

Thus the final conclusion to this paper is a premise: that design can be studied in terms of process, and in terms of system, and that such studies both answer and generate structural, "visual," and cognitive questions.

\section{NOTES}

\footnotetext{
${ }^{1}$ This study is a revised version of a senior honors thesis submitted to Harvard University in 1971 . The original study was financed by a National Science Foundation research grant obtained through the Harvard Anthropology Department, and was largely carried out using the resources of the Museum of Northern Arizona's Research Center. This manuscript was prepared while I was on a fellowship program at the Smithsonian Institution in Washington, D.C. I would therefore like to acknowledge the support of all of the above institutions. In addition, I would like to thank those people who assisted me at the Museum of Northern Arizona for their help, Dr. Jeremy Sabloff who was my thesis advisor at Harvard for his encouragement, and Professor Sol Worth of the Annenberg School of Communications for his generous assistance and constructive comments both on this manuscript and on a related verification project conducted at the Summer Institute of Visual Communications in Sante Fe, New Mexico, during the summer of 1972 .

2I am admittedly interpreting both Arnheim's and Lévi-Strauss' work selectively, and in that sense make no pretense of accurately representing either of their frameworks. In addition, having discussed the work of Whorf with Arnheim on one occasion, I know for a fact that despite all the possible congruences which I see, he is aware of irreconcilable differences (personal communication 1971). For a discussion of some of these differences (cf. Worth 1974:276-279).

${ }^{3}$ I am using Hopi (in reference both to pottery and its makers) to indicate both the Hopi and the Hopi-Tewa, and descendents of the group of Tewas who migrated to the First Mesa town of Hano some
} 
300 years ago. Although they still maintain a certain cultural autonomy, the pottery tradition is, for the purpose of this analysis, essentially the same as the Hopi. Some of the pots illustrated in this article, are Hopi-Tewa.

${ }^{4}$ I have generally not cited specific sources for this and the preceding two technical sections, because the information is such a conglomeration of so many sources, most of which are listed in the bibliography.

${ }^{5}$ In particular, Shepard (1956:269) defines band patterns in terms of operations by which the repetition occurs, e.g.: translation (foreward movement without change in orientation), reflection (folding along an axis so as to produce a mirror-image), bifold rotation (a $180^{\circ}$ rotation of a single axis), as well as various combinations of the above. These seem to be predominantly conceptual or cognitive operations, rather than actual physical operations. Symmetries of total patterns could thus conceivably be classified in more than one way, depending upon what one defined as the 'element' which is subjected to the operation. In this study, I have concentrated both on the operation of rotation $\left(180^{\circ}\right.$ or otherwise) and on the division or creation of fields which imply rotation, although the resulting symmetry (if there is one) could often be classified as 'radial' just as easily as 'rotational.'

${ }^{6}$ The terms we and our, as used to refer to citations of Whorf (1941), specifically refer to the group which Whorf has labeled "Standard Average European." This category includes English, French, German, and other European languages, the assumption being that all such languages use the same basic distinctions (Whorf 1941:78) in the grammatical constructions and categories discussed, and differentiated from the Hopi language. In other citations from Whorf, the same referent is probably applicable, but it is not specified explicitly.

${ }^{7}$ This experimental procedure, including the use of film to record the drawing process, was devised and tested in preliminary fashion during the summer of 1972, at the Summer Institute in Visual Anthropology, held in Sante Fe, New Mexico.

${ }^{8}$ This study forms the basis of a doctoral dissertation for the University of British Columbia.

\section{REFERENCES CITED}

Arnheim, Rudolf

1966 Toward a Psychology of Art. Berkeley \& Los Angeles: University of California Press.

Bartlett, Katherine

1936 How to Appreciate Hopi Crafts. The Flagstaff Museum of Arizona Museum Notes 9(1)1-8.

Bunzel, Ruth L.

1929 The Pueblo Potter: A Study of Creative Imagination in Primitive Art. Columbia University Contributions to Anthropology, Vol. VIII. New York: Columbia University Press.

Chapman, Kenneth

1959 The Line-Break, Problem Child in Pueblo Pottery. EI Palacio, Sante Fe 58(9)251-289.

Fewkes, J. Walter

1898 The Feather Symbol in Ancient Hopi Designs. American Anthropologist (o.s.) 11:1-14.

1910 The Butterfly in Hopi Myth and Ritual. American Anthropologist 12:576-594.

Hayes, E. Nelson, and Tanya Hayes (Eds.)

1970 Claude Lévi-Strauss: The Anthropologist as Hero. Cambridge, MA: MIT Press.

Hough, Walter

1919 The Hopi Indian Collection in the United States National Museum. United States National Museum Proceedings 54:235-396

Holm, Bill

1965 Northwest Coast Art: An Analysis of Form. Seattle: University of Washington Press.

Hubert, Virgil

1937 An Introduction to Hopi Pottery Design. Flagstaff Museum of Northern Arizona Museum Notes 10:1-40.

Lévi-Strauss, Claude

1960 On Manipulated Sociological Models. Bijdragen tot de taal-, land- en Volkenkunde. 116(1)45-54.
1966 The Savage Mind. Chicago: University of Chicago Press.

1967 Structural Anthropology. Jacobson and Schoepf, trans. New York: Anchor Books.

1969 The Elementary Structures of Kinship. Revised Edition. R. Needham, Ed. Bell and Von Sturmes, trans. Boston: Beacon Press.

Ortiz, Alfonso

1972 Ritual Drama and the Pueblo World View. In New Perspectives on the Pueblos. A. Ortiz, Ed. Albuquerque: University of New Mexico Press. pp. 135-161.

Shepard, Anna O.

1956 Ceramics for the Archeologist. Carnegie Institution of Washington Publication 609

Sapir, Edward

1929 The Status of Linguistics as a Science. Language 4:207-214.

Sides, Dorothy

1961 Decorative Art of the Southwestern Indians. New York: Dover.

Sikorski, Katherine

1968 Modern Hopi Pottery. Utah State University Monograph Series 15(2).

Thompson, Laura, and Alice Joseph

1944 The Hopi Way. Chicago: University of Chicago Press.

Thompson, Laura

1945 Logico-Aesthetic Integration in Hopi Culture. American Anthropologist 47:540-553.

Whorf, Benjamin

1936 The Punctual and Segmentative Aspects of Verbs in Hopi. Reprinted in Language, Thought and Reality. John B. Carroll, Ed. Cambridge, MA: Technology Press of MIT (1956). pp. 51-64.

1938 Some Verbal Categories of Hopi. In Language, Thought and Reality. John B. Carroll, Ed. Cambridge, MA: Technology Press of MIT (1956). pp. 112-124.

1940 Science and Linguistics. In Language, Thought and Reality. John B. Carroll, Ed. Cambridge, MA: Technology Press of MIT (1956). pp. 207-219.

1941 The Relation of Habitual Thought to Language. In Language, Culture and Personality, essays in memory of Edward Sapir. Leslie Spier, Ed. Menasha, WI: Banta. pp. 75-93.

1950 An American Indian Model of the Universe. International Journal of American Linguistics 16:67-72.

Worth, Sol

1974 The Uses of Film in Education and Communication. In Media and Symbols: The Form of Expression, Communication and Education. Seventy-third Yearbook of the National Society for the Study of Education. pp. 271-302.

\section{FIGURE CREDITS}

Most of the pottery shown in the illustrations is from the collection of the Museum of Northern Arizona in Flagstaff. These pots are labeled by the abbreviation MNA in the following list and are followed by their catalogue numbers. All other pottery, listed as "modern (1970)" in the following list, appeared at the Craft Exhibit at the Museum of Northern Arizona during the summer of 1970. All photographs and drawings are by the author. Figures 5 and 21 are schematic drawings.

Figure 1 - modern bowl, MNA Craft Exhibit (1970).

Figures 2, 3 - MNA cat. \#2208/E1503.

Figure 4 - modern bowl, MNA Craft Exhibit (1970).

Figure 5-schematic drawing by the author.

Figure 6 - MNA cat. \#225/1015.

Figures 7, 8-MNA cat. \#1015/E556.

Figure 9 - MNA cat. \#1014/E515.

Figures 10, 11 - MNA cat. \#774/E2630.

Figures 12, 13 - MNA cat. \#918/E458.

Figure 14 - exterior panel from MNA cat. \#255/1013. Figure 15 - interior design from MNA cat. \#1015/E521. Figure 16 - interior design from MNA cat. \#1026/E615. Figure 17 - modern bowl, MNA Craft Exhibit (1970).

Figure 18 - MNA cat. \#782/E157.

Figure 19, 20 - modern bowls, MNA Craft Exhibit (1970).

Figure 21 - schematic drawing by the author. 